\title{
Evaluation of the atmospheric transport in a GCM using radon measurements: sensitivity to cumulus convection parameterization
}

\author{
K. Zhang ${ }^{1,4}$, H. Wan ${ }^{2}$, M. Zhang ${ }^{3}$, and B. Wang ${ }^{1}$ \\ ${ }^{1}$ LASG, Institute of Atmospheric Physics, Chinese Academy of Sciences, Beijing, China \\ ${ }^{2}$ International Max Planck Research School on Earth System Modelling, Hamburg, Germany \\ ${ }^{3}$ LAPC, Institute of Atmospheric Physics, Chinese Academy of Sciences, Beijing, China \\ ${ }^{4}$ Graduate School of the Chinese Academy of Sciences, Beijing, China
}

Received: 29 November 2007 - Published in Atmos. Chem. Phys. Discuss.: 5 February 2008

Revised: 15 April 2008 - Accepted: 10 May 2008 - Published: 29 May 2008

\begin{abstract}
The radioactive species radon $\left({ }^{222} \mathrm{Rn}\right)$ has long been used as a test tracer for the numerical simulation of large scale transport processes. In this study, radon transport experiments are carried out using an atmospheric GCM with a finite-difference dynamical core, the van Leer type FFSL advection algorithm, and two state-of-the-art cumulus convection parameterization schemes. Measurements of surface concentration and vertical distribution of radon collected from the literature are used as references in model evaluation.

The simulated radon concentrations using both convection schemes turn out to be consistent with earlier studies with many other models. Comparison with measurements indicates that at the locations where significant seasonal variations are observed in reality, the model can reproduce both the monthly mean surface radon concentration and the annual cycle quite well. At those sites where the seasonal variation is not large, the model is able to give a correct magnitude of the annual mean. In East Asia, where radon simulations are rarely reported in the literature, detailed analysis shows that our results compare reasonably well with the observations.
\end{abstract}

The most evident changes caused by the use of a different convection scheme are found in the vertical distribution of the tracer. The scheme associated with weaker upward transport gives higher radon concentration up to about $6 \mathrm{~km}$ above the surface, and lower values in higher altitudes. In the lower part of the atmosphere results from this scheme does not agree as well with the measurements as the other scheme. Differences from $6 \mathrm{~km}$ to the model top are even larger, although we are not yet able to tell which simulation is better due to the lack of observations at such high altitudes.

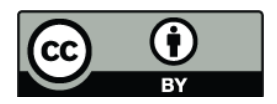

Correspondence to: $\mathrm{K}$. Zhang (kai.zhang@zmaw.de)

\section{Introduction}

The interaction between atmospheric chemistry and climate change has been a hot topic in recent years in climate research and environmental sciences. Both chemical transport models (CTMs) and general circulation models (GCMs) have been used to address this issue. Typically, a large number of chemical species, either inert or reactive, are involved. A realistic simulation of the distribution, lifetime and climate effects of these species relies on sound information about the emissions, good knowledge of the transformation mechanisms, and reliable representation of the atmospheric transport, the last of which is the focus of this paper. The most important transport processes in a numerical model include large scale advection, cumulus convection and vertical diffusion. These processes redistribute the chemical species at a global scale and provide background concentrations for the chemical reactions and the subsequent processes happening in the climate system. Therefore a detailed validation of the transport processes is an indispensable step before a model is put into any practical application.

Radon $\left({ }^{222} \mathrm{Rn}\right)$ has long been used as tracer in studies of atmospheric transport. As a noble gas and the radioactive decay product of radium $\left({ }^{226} \mathrm{Ra}\right)$, it exists in most types of rock and soil, and is emitted from ice-free land surface with a rather uniform rate. It has a half-life time of 3.82 days - similar to some important reactive chemicals, e.g. $\mathrm{SO}_{2}-$ but is removed from the atmosphere only by radioactive decay. The relatively simple life cycle renders radon a suitable indicator for transport tests. Meanwhile, measurements of atmospheric radon concentration available from distributed observatories provide a good reference for model evaluation.

In the 1990's, two coordinated model intercomparisons of radon transport simulations were carried out, which provided an overview of the models' performance although the

Published by Copernicus Publications on behalf of the European Geosciences Union. 
observations available at that time were quite limited (Jacob et al., 1997; Rasch et al., 2000). A number of publications reported on evaluation studies for individual transport models (Mahowald et al. 1997; Dentener et al. 1999; Considine et al. 2005, among others). In addition, radon has been used as an indicator to investigate other issues. For example, Feichter and Crutzen (1990) evaluated a convective transport scheme designed for a CTM driven by monthly mean climatology; Mahowald et al. (1995) compared seven cumulus convection parameterizations in a one-dimensional column model through comparison of the simulated radon profiles. Olivié et al. (2004) tested four different sets of vertical diffusion coefficients in the TM3 chemical transport model. The work by Genthon and Armengaud (1995) was the first one in the literature using radon to test and compare the tracer transport processes in GCMs.

In this study, radon transport experiment is carried out with the Gridpoint Atmospheric Model of IAP-LASG (GAMIL) developed in the State Key Laboratory of Numerical Modeling for Atmospheric Sciences and Geopgysical Fluid Dynamics (LASG) at the Institute of Atmospheric Physics (IAP) of the Chinese Academy of Sciences.

The overall ability of this global model to represent the mass distribution of radon and its seasonal variability is examined. The work presented here differs from previous studies in three major aspects: first, a new general circulation model with some unique features is used; second, we are particularly interested in the comparison between two state-ofthe-art cumulus convection parameterization schemes. Last but not least, the validation data in this work include not only the frequently cited observations obtained before 1990 , but also new measurements published in recent years (see Sect. 3).

So far CTMs have been used extensively in atmospheric chemistry studies. However, independency between the external meteorological data and the transport scheme within a transport model sometimes leads to significant errors. This problem can eventually be solved in GCMs if the NavierStokes equations and the tracer mass budget are discretized in a consistent way. As for the feedback of chemistry-related processes to atmospheric circulation and its impact on future climate change, the instantaneous interactions in GCMs are certainly advantageous.

GAMIL is a global atmospheric GCM with a finite difference dynamical core. Most of the physics parameterizations come from the National Center for Atmospheric Research (NCAR) Community Atmosphere Model version 2 (CAM2, Collins et al., 2003) which is a spectral transform model. Although sharing most parts of the physics package makes GAMIL similar to CAM2 in many aspects of the model climate, distinctions due to differences between the dynamical cores are still clearly detectable. The GAMIL model appears to have its particular merits in simulating the Asian monsoon circulation (Wan et al., 2006; Yang et al., 2007). As an example, we present in Fig. 1 summer precipitation in East
Asia, where severe problems in the Himalaya/Tibetan region in many other models (see, e.g., Fig. 1d here and Fig. 2 in Tost et al. 2006) are evidently reduced (Fig. 1e, f) in GAMIL. So far the GAMIL model has been used in atmosphere-alone applications such as AMIP (Atmospheric Model Intercomparison Project ${ }^{1}$ ) and SMIP (Seasonal Prediction Model Intercomparison Project ${ }^{2}$ ) experiments (Wan et al., 2006; Yang et al., 2007; Shi et al., 2008). It is also the atmosphere component of the Flexible Global Ocean-Atmosphere-Land System (FGOALS, Yu et al., 2008) which has been used in the IPCC AR4 experiments (see, e.g., van Ulden and van Oldenborgh, 2006; Yu et al., 2008). Currently an aerosol module is under development for GAMIL, from which arises the motivation for transport validation.

Cumulus convection has a profound impact on the hydrological cycle of the climate system, the dynamics of the atmospheric circulation, and the mass budget of chemical species. It is also one of the major sources of uncertainty in climate simulations. In the past decades, a number of schemes have been proposed to parameterize this process in large scale atmospheric GCMs (see Arakawa 2004 for a review), among which the most widely used in recent years are probably the schemes by Tiedtke (1989) and Zhang and McFarlane (1995). For example, CAM2 and MATCH (Rasch et al., 1997) utilize the Zhang-McFarlane scheme combined with Hack's proposal (1994) (hereafter ZMH); ECHAM4 and 5 (Roeckner et al., 1996, 2003, 2006) employ the Tiedtke scheme with further modifications by Nordeng (1994) (hereafter TN). The algorithm in the ECMWF operational model IFS is also a further development of the Tiedtke (1989) scheme (Bechtold et al., 2004). The ZMH and TN schemes both take the mass-flux form, but have differences in the closure method, triggering conditions for convection and formulations for precipitations. Summaries of the details can be found in Sect. 2b of Liu et al. (2005) and Table 1 of Tost et al. (2006). After a lot of comparison studies with various models, it has been found that both schemes have strengths and weaknesses, and the actual performance is model-dependent. Interestingly, we saw Liu et al. (2005) applying the TN scheme from ECHAM4 to CAM2, and later Tost et al. (2006) implementing the ZMH scheme in ECHAM5.

The GAMIL model also has these two convection schemes in its physics package. In the AMIP simulations the TN scheme leads to a significantly improved rainfall simulation in the Indian and East Asia monsoon regions, in terms of both spatial distribution and temporal variation (Fig. 1; Wan et al., 2006). On the other hand, due to the resulting changes in water vapor and cloud distribution, the top-of-atmosphere (TOA) energy balance is violated, indicating necessity of further tuning. As for the impact on tracer transport, no comparison has been done for the GAMIL model before this work. There have been publications investigating impact of

\footnotetext{
${ }^{1}$ http://www-pcmdi.llnl.gov/projects/amip/index.php

${ }^{2}$ http://grads.iges.org/ellfb/SMIP2/smip2.top.html
} 
(a) CMAP data (1979-1998)

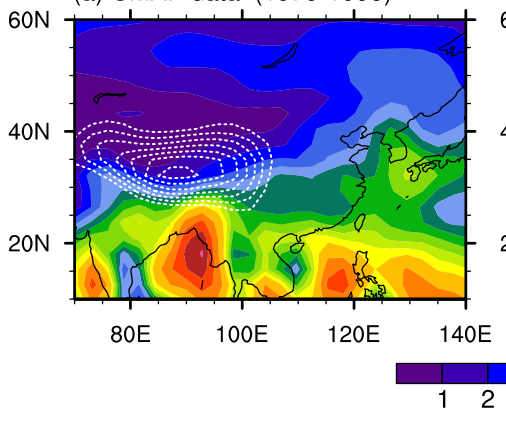

(b) TRMM data (1998-2002)

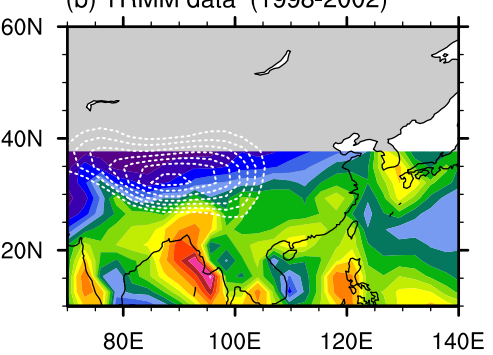

(c) In situ data (1979-1998)

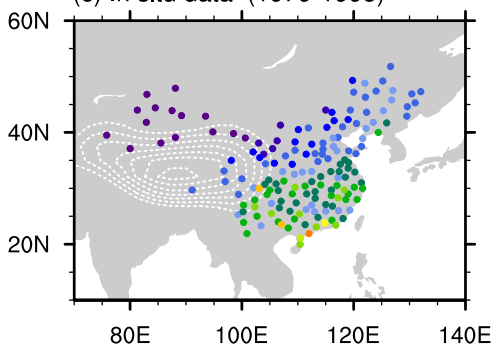

(d) CAM2 (AMIP 1979-1998)

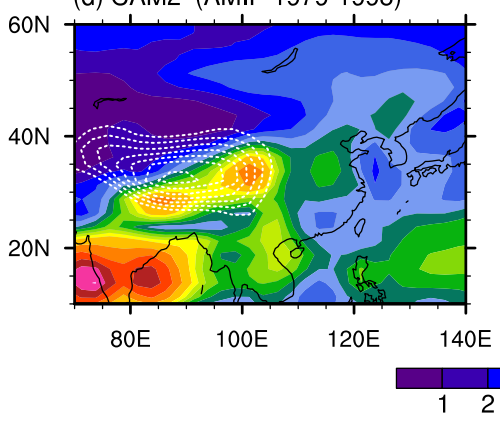

(e) GAMIL-ZMH (AMIP 1979-1998)

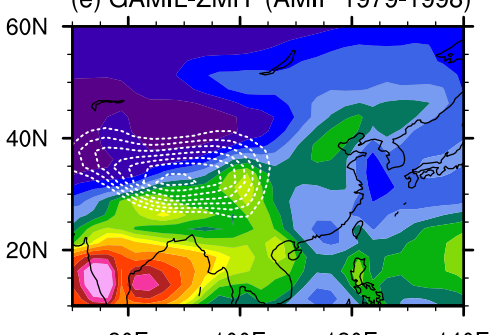

(f) GAMIL-TN (AMIP 1979-1998)

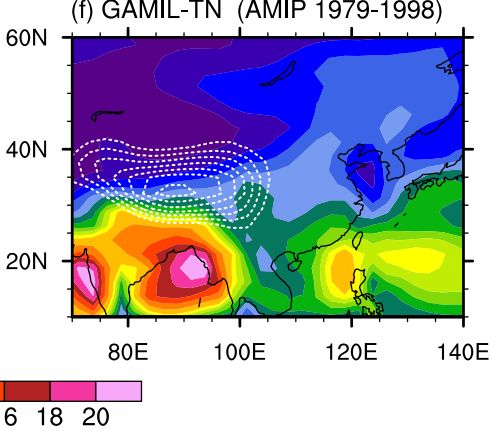

Fig. 1. Observed and simulated summer precipitation (June-July-August average, unit: mm day ${ }^{-1}$ ) in East Asia: (a) the CPC Merged Analysis of Precipitation (CMAP, http://www.cdc.noaa.gov/cdc/data.cmap.html); (b) the Tropical Rainfall Merged Mission (TRMM,http:// trmm.gsfc.nasa.gov/trmm_rain/Events/trmm_climatology_3B43.html); (c) in situ measurements at 160 observatories in China; (d) simulation by CAM2; (e) simulation by GAMIL with the Zhang-McFarlane-Hack cumulus convection scheme; (f) simulation by GAMIL with the Tiedtke-Nordeng convection scheme. The plotted CMAP and in situ data are averages over the 1979-1998 period. The TRMM data are the 1998-2002 average obtained from the NCAR AMWG diagnostic package. Model simulations are the 1979-1998 average from AMIP experiments. The dashed white contours indicate surface topography in the GCMs (from 2000 to $5000 \mathrm{~m}$ above sea level, with an interval of $500 \mathrm{~m})$.

convection on radon transport, but using other parameterization schemes (Feichter and Crutzen, 1990; Mahowald et al., 1995). As for comparison between ZMH and TN, only the impact on the general circulation has been investigated (e.g., Liu et al., 2005; Song, 2005; Tost et al., 2006). In this study we put our focus on the sensitivity of radon transport.

The rest of the paper is organized as follows: more information about the model and the experiments is provided in Sect. 2. The radon measurements used as reference are introduced in Sect. 3. Section 4 describes the simulated global radon distributions. Comparison of surface concentration with observation is presented in Sect. 5. Analysis of the vertical profiles is given in Sect. 6. Section 7 summarizes the study and draws the conclusions.

\section{Model and experiments}

The prognostic variables of the hydrostatic GAMIL model are the horizontal wind, temperature, surface pressure and the mixing ratio of tracers. The spatial discretization on a Ctype latitude-longitude grid originated from the work of Zeng et al. (1985). A coordinate transformation in the meridional direction was introduced by Wang et al. (2004) to enlarge the zonal grid sizes in the polar regions and thus improve the computational stability. The model version used in this study has 128 longitudes and 60 latitudes. Locations of the grid points between $66^{\circ} \mathrm{N}$ and $66^{\circ} \mathrm{S}$ are exactly the same as the T42 Gaussian grid. In the vertical, the computational domain extends from the earth's surface to $2.194 \mathrm{hPa}$, unevenly divided into 26 layers in a pressure-based sigma coordinate. Roughly speaking, there are 3 layers in the boundary layer, 14 in the free troposphere, and 9 in the stratosphere. A semiimplicit time stepping scheme conserving the total effective energy was introduced by Wang and Ji (2006). (The original text was in Chinese. A short summary in English can be found in Zhang et al. 2008.) The large scale advection of water vapor is handled by the Two-step Shape-Preserving Advection Scheme (TSPAS, Yu 1994). The Flux-Form SemiLagrangian (FFSL) transport algorithm proposed by Lin and Rood (1996) has also been introduced into this model (Zhang et al., 2008). 


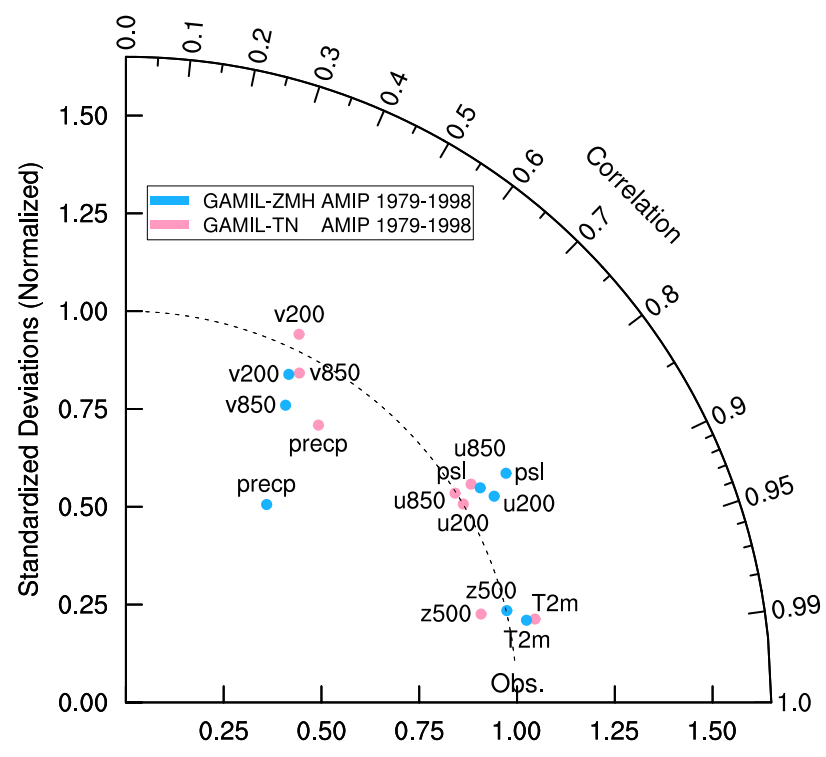

Fig. 2. Taylor diagram showing the space-time variability in AMIP simulations performed with two versions of the GAMIL model using the Zhang-McFarlane-Hack and the Tiedtke-Nordeng convection schemes, respectively. The CMAP precipitation data and the NCEP/DOE Reanalysis-II are used as reference (referred to as "Obs." in the diagram). The statistics are calculated using monthly mean data from January 1979 to December 1998 between $60^{\circ} \mathrm{S}$ and $60^{\circ} \mathrm{N}$. The meteorological variables shown include sea level pressure ("psl”), 2-m temperature (“T2m"), precipitation rate ("precp"), $500 \mathrm{hPa}$ geopotential height ("z500"), as well as the zonal and meridional wind at $200 \mathrm{hPa}$ and $850 \mathrm{hPa}$ (labeled as "u200", "v200", "u850", and "v850", respectively).

As mentioned in the previous section, most of the physics parameterizations are the same as in CAM2, except that the TN convection scheme is also implemented. The boundary layer turbulent mixing scheme is an explicit, non-local as described in Holtslag and Boville (1993) and Boville and Bretherton (2003). Other details about the physics package can be found in Collins et al. (2003).

The overall performance of the two versions of GAMIL in general circulation simulation is shown in Fig. 2 with a Taylor diagram (Taylor, 2001). Cosine of the polar angle of a point in the diagram equals the correlation coefficient between simulation and reanalysis; The radial distance from the origin indicates the standard deviation of the simulated field normalized by that of the corresponding reanalysis. The statistics indicated in in Fig. 2 are calculated using monthly mean data between $60^{\circ} \mathrm{S}$ and $60^{\circ} \mathrm{N}$ in AMIP simulations covering the period from January 1979 to December 1998. Judging from this diagram, the two model versions are of similar quality, except that the variance error of precipitation is significantly reduced in the TN simulation. The correlation between model result and the NCEP/DOE Reanalysis-II is about 0.98 for $2-\mathrm{m}$ temperature (labeled as "T2m" in the diagram) and 0.97 for $500 \mathrm{hPa}$ geopotential height ("z500"); The correlation is around 0.85 for sea level pressure ("psl"), as well as for the zonal wind at the $850 \mathrm{hPa}$ ("u850") and $200 \mathrm{hPa}$ level ("u200"). Simulations of the meridional wind ("v850" and "v200") are less accurate. Precipitation rates given by the model ("precp") are correlated with the CMAP data Xie and Arkin (1997) with a coefficient of about 0.57. The simulated space-time variances are in general in good agreement with the reanalysis, except that the variability in precipitation is underestimated. The performance indicated in Fig. 2 is similar to the AMIP I multi-model ensembles as shown in Fig. 14 in Gates et al. (1999). For further details of the climate simulations with GAMIL, the interested readers are referred to the work by Wan et al. (2006) and Yang et al. (2007).

Apart from the transport processes, emission is also an important factor that determines radon distribution in the atmosphere. Based on measurements of ${ }^{222} \mathrm{Rn}$ concentration and ${ }^{210} \mathrm{~Pb}$ deposition flux, previous studies have derived estimates of continental radon emission ranging from 0.71 to 1.2 atom $\mathrm{cm}^{-2} \mathrm{~s}^{-1}$ (Turekian et al., 1977; Lambert et al., 1982).

For validation of global models, the emission is generally assumed to be spatially uniform $\left(1\right.$ atom $\left.\mathrm{cm}^{-2} \mathrm{~s}^{-1}\right)$ from icefree land surfaces, which is believed to be accurate within $25 \%$ globally and within a factor of 2 regionally (Jacob et al., 1997). In this study we follow the recommendation of the World Climate Research Program (WCRP) Cambridge Workshop of 1995 (Rasch et al., 2000): The continental emission is set to 1 atom $\mathrm{cm}^{-2} \mathrm{~s}^{-1}$ between $60^{\circ} \mathrm{S}$ and $60^{\circ} \mathrm{N}$ and 0.5 atom $\mathrm{cm}^{-2} \mathrm{~s}^{-1}$ between $60^{\circ} \mathrm{N}$ and $70^{\circ} \mathrm{N}$, except for Greenland. Emission over the oceans and the Antarctica is assumed to be zero.

Some modelling studies have indicated that taking into account the latitudinal and regional gradients of radon emission could lead to a more realistic simulation of the surface concentration, especially at high-latitude sites (e.g. Lee and Feichter, 1995; Guelle et al., 1998; Conen and Robertson, 2002). However, we stick to the WCRP 1995 settings so that there are more information available from other models to which our results can be compared directly.

In this study, we conduct climate simulations using the GAMIL model with radon treated as passive tracer. The sea surface temperature (SST) and sea ice data as boundary conditions are the 1979-2001 average without interannual variation. The original data at $1^{\circ} \times 1^{\circ}$ resolution are obtained from the Program for Climate Model Diagnosis and Intercomparison (PCMDI, http://www-pcmdi.llnl.gov/ projects/amip/index.php) and interpolated to the model grid using area-weighted interpolation. Meteorological fields at the initial time step are interpolated from the ERA40 reanalysis at 1 January 1979 00:00 UTC. The initial concentration of radon is zero. Two six-year simulations are conducted using the ZMH and TN convection scheme, respectively, of which the first year is discarded as the spin-up phase. All 
Table 1. Detailed information about the surface radon measurements used in this study. Regarding data source, DWD stands for Deutscher Wetterdienst (German Weather Service); IPSL for Institut Pierre-Simon Laplace; EML for DOE/Environmental Measurements Laboratory. Location of these site are also plotted in Fig. 3 and Fig. 4.

\begin{tabular}{|c|c|c|c|c|}
\hline Site & Location & Type & Period & Source \\
\hline Beijing, China & $116^{\circ} 12^{\prime} \mathrm{E}, 39^{\circ} 36^{\prime} \mathrm{N}$ & Continental & 2003 & Zhang et al. (2004) \\
\hline Socorro, United States & $106^{\circ} 54^{\prime} \mathrm{W}, 34^{\circ} 06^{\prime} \mathrm{N}$ & Continental & $1951-1956$ & Wilkening (1959) \\
\hline Cincinnati, United States & $84^{\circ} 30^{\prime} \mathrm{W}, 39^{\circ} 08^{\prime} \mathrm{N}$ & Continental & $1959-1963$ & Gold et al (1964) \\
\hline Para, Brazil & $55^{\circ} 00^{\prime} \mathrm{W}, 02^{\circ} 54^{\prime} \mathrm{S}$ & Continental & $2000.07-2004.12$ & Martens et al. (2004) \\
\hline Hohenpeissenberg, Germany & $11^{\circ} 01^{\prime} \mathrm{E}, 47^{\circ} 48^{\prime} \mathrm{N}$ & Continental & 1999-2005 & DWD (Zellweger et al., 2006) \\
\hline Puy de Dome, France & $03^{\circ} 00^{\prime} \mathrm{E}, 48^{\circ} 30^{\prime} \mathrm{N}$ & Continental & 2002 & IPSL (Ramonet et al., 2003) \\
\hline Amsterdam Island, France & $77^{\circ} 32^{\prime} \mathrm{E}, 37^{\circ} 47^{\prime} \mathrm{S}$ & Oceanic & $1981-2001$ & IPSL (Ramonet et al., 2003) \\
\hline Crozet Island & $51^{\circ} 51^{\prime} \mathrm{E}, 46^{\circ} 27^{\prime} \mathrm{S}$ & Oceanic & 1993 & Dentener et al. (1999) \\
\hline Kerguelen & $70^{\circ} 18^{\prime} \mathrm{E}, 49^{\circ} 18^{\prime} \mathrm{S}$ & Oceanic & 1993 & Dentener et al. (1999) \\
\hline Bermuda, United States & $64^{\circ} 39^{\prime} \mathrm{W}, 32^{\circ} 22^{\prime} \mathrm{N}$ & Oceanic & 1991-1996 & EML (Hutter et al., 1995) \\
\hline Dumont d'Urvllle & $140^{\circ} 00^{\prime} \mathrm{E}, 66^{\circ} 00^{\prime} \mathrm{S}$ & Oceanic & $1978.12-1979.11$ & Heimann et al. (1990) \\
\hline Mauna Loa, United States & $155^{\circ} 35^{\prime} \mathrm{W}, 19^{\circ} 32^{\prime} \mathrm{N}$ & Oceanic & 1991-1996, 2001 & $\begin{array}{l}\text { EML (Hutter et al., 1995) and } \\
\text { Zahorowski et al. (2005) }\end{array}$ \\
\hline Gosan, Korea & $126^{\circ} 12^{\prime} \mathrm{E}, 33^{\circ} 18^{\prime} \mathrm{N}$ & Coastal and East Asia & 2001 & Zahorowski et al. (2005) \\
\hline Hong Kong, China & $114^{\circ} 18^{\prime} \mathrm{E}, 22^{\circ} 12^{\prime} \mathrm{N}$ & Coastal and East Asia & 2001 & Zahorowski et al. (2005) \\
\hline Beijing, China & $116^{\circ} 12^{\prime} \mathrm{E}, 39^{\circ} 36^{\prime} \mathrm{N}$ & East Asia & $\begin{array}{l}1988.11-1989.11 \\
1991.04-1992.04\end{array}$ & $\begin{array}{l}\text { Jin et al. (1998) } \\
\text { Jin et al. (1998) }\end{array}$ \\
\hline Huhehaote, China & $111^{\circ} 42^{\prime} \mathrm{E}, 40^{\circ} 48^{\prime} \mathrm{N}$ & East Asia & same as avobe & Jin et al. (1998) \\
\hline Changchun, China & $125^{\circ} 12^{\prime} \mathrm{E}, 43^{\circ} 54^{\prime} \mathrm{N}$ & East Asia & same as above & Jin et al. (1998) \\
\hline Nanjing, China & $118^{\circ} 48^{\prime} \mathrm{E}, 32^{\circ} 00^{\prime} \mathrm{N}$ & East Asia & same as above & Jin et al. (1998) \\
\hline Xi'an, China & $108^{\circ} 54^{\prime} \mathrm{E}, 34^{\circ} 18^{\prime} \mathrm{N}$ & East Asia & same as above & Jin et al. (1998) \\
\hline Wuhan, China & $114^{\circ} 06^{\prime} \mathrm{E}, 30^{\circ} 36^{\prime} \mathrm{N}$ & East Asia & same as above & Jin et al. (1998) \\
\hline Guiyang, China & $106^{\circ} 42^{\prime} \mathrm{E}, 26^{\circ} 36^{\prime} \mathrm{N}$ & East Asia & same as above & Jin et al. (1998) \\
\hline Shanghai, China & $121^{\circ} 24^{\prime} \mathrm{E}, 31^{\circ} 12^{\prime} \mathrm{N}$ & East Asia & same as above & Jin et al. (1998) \\
\hline Fuzhou, China & $119^{\circ} 18^{\prime} \mathrm{E}, 26^{\circ} 06^{\prime} \mathrm{N}$ & East Asia & same as above & Jin et al. (1998) \\
\hline Gaoxiong, China & $120^{\circ} 48^{\prime} \mathrm{E}, 22^{\circ} 00^{\prime} \mathrm{N}$ & East Asia & same as above & Jin et al. (1998) \\
\hline Cape Grim, Tasmania & $144^{\circ} 41^{\prime} \mathrm{E}, 40^{\circ} 40^{\prime} \mathrm{S}$ & Coastal & $2000-2001$ & Zahorowski and Whittlestone (1999) \\
\hline Bombay,India & $72^{\circ} 48^{\prime} \mathrm{E}, 18^{\circ} 54^{\prime} \mathrm{N}$ & Coastal & $1966-1976$ & Mishra et al. (1980) \\
\hline Livermore, United States & $121^{\circ} 48^{\prime} \mathrm{W}, 37^{\circ} 42^{\prime} \mathrm{N}$ & Coastal & $1965.05-1966.08$ & Lindeken (1966) \\
\hline Mace Head, Ireland & $09^{\circ} 54^{\prime} \mathrm{W}, 53^{\circ} 18^{\prime} \mathrm{N}$ & Coastal & $1995-2001$ & IPSL (Ramonet et al., 2003) \\
\hline
\end{tabular}

the diagnostics presented in this study are based on the 6-h output of the last five years.

It is worth noting that in our experiments the large scale advection of radon is handled by the van Leer type FFSL scheme. In an earlier study (Zhang et al., 2008) it has been found that when the TSPAS scheme is used, significant biases occur in idealized test cases and in the radon transport simulations, especially in the polar regions and in the upper part of the atmosphere. In contrast, the FFSL scheme produces much more reasonable results. A natural decision following that work may be to replace the old scheme by FFSL for all tracers in the model. However, the complicated feedback of water vapor to the atmospheric general circulation will probably lead to some changes in the climate state as well (Rasch and Kristjansson, 1998). So far in all the other applications of the GAMIL model the TSPAS advection scheme have been used. Given that radon is a passive tracer in this study, we use TSPAS for water vapor and FFSL for radon, so that the GCM employed here is exactly the same as its "IPCC version".

\section{Radon measurements}

This section briefly introduces the observational data used for comparison with the model simulations. The measurements are of two types: radon concentration near the earth's surface and the vertical profiles.

\subsection{Surface concentration}

Surface radon concentration at 27 sites worldwide are collected from the literature for use here. Basic information about these measurements is presented in Table 1, Fig. 3 and Fig. 4. At 18 sites monthly mean concentration is available. Since some of these monthly means are calculated from measurements at higher frequencies (e.g. hourly or 6-h data), the standard deviation of all the samples within the same month are also calculated and plotted. For the other 9 sites and Beijing which are city stations in China, the annual mean has been reported by Jin et al. (1998).

It should be pointed out that the heights and measuring methods differ significantly from site to site. The details will 


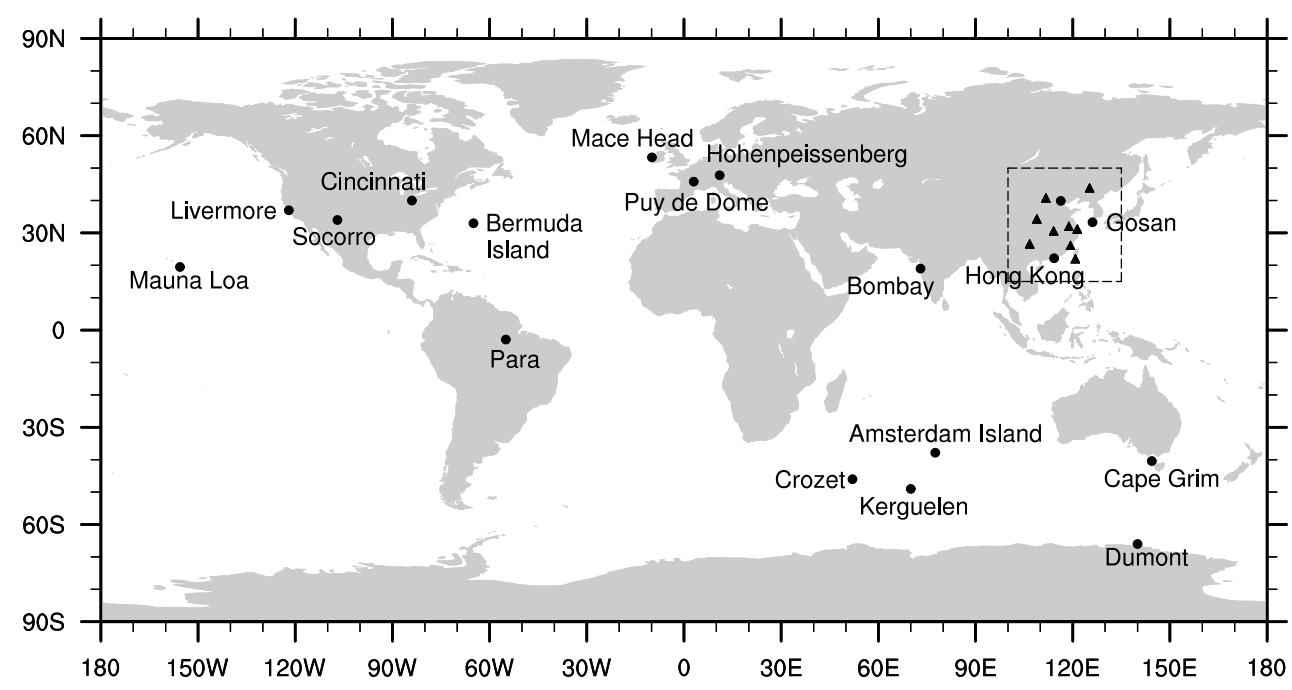

Fig. 3. Locations of the surface radon measurements used in this study. Dots indicate the sites where monthly data are available. Triangles denote the sites where only the annual mean has been reported. The area in the dashed frame is enlarged in Fig. 4.

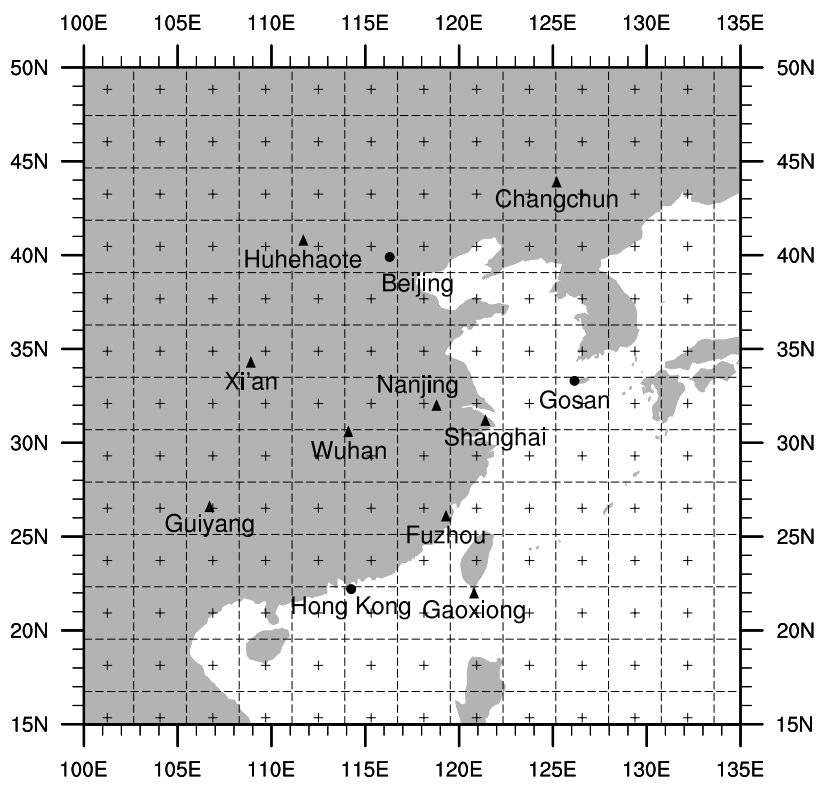

Fig. 4. Locations of the surface radon concentration measurements in East Asia. Dots indicate the sites where monthly data are available. Triangles denote the sites where only the annual mean has been reported. Gray crosses on the map indicate grid points in the GCM. The dashed lines are the boundary of grid cells.

be mentioned in the following sections during the analysis. For a complete description of the measurements, the readers are referred to the publications listed in Table 1.

Another important fact to note is that not all the sites listed in Table 1 have multi-year continuous observations. It is well-known that the interannual variability of the atmospheric general circulation is high. The same must be true for radon concentration at specific locations. However, radon observation is quite limited; Moreover, our simulations proceed only six years and the SST and sea ice forcing is repeated from year to year. It is therefore impossible to reasonably estimate the uncertainty associated with interannual variation from either the measurements or our experiments. During the discussion on model evaluation in the following sections we have to take this into account and bear in mind that the monthly means observed in a specific year at a specific station may deviate significantly from the long-term climatology.

\subsection{Vertical profiles}

Observations of the vertical distribution of radon are rare. Summer and winter profiles of the Northern Hemisphere have been compiled by Liu et al. (1984), who computed the average of individual measurements at different continental locations from 1950 to 1972 . The winter profile is the average of 7 sites and the summer profile 23 sites. Although the data are relatively old, they are quite often cited in related studies.

Kritz et al. (1998) presented a group of free tropospheric radon profiles measured by aeroplane in the summer of 1994 from the earth's surface till $11.5 \mathrm{~km}$ altitude. The starting measuring place was Moffett Field $\left(37.4^{\circ} \mathrm{N}, 122.0^{\circ} \mathrm{W}\right)$ in California, USA. 11 profiles were obtained from June to August 1994. We use the average of the 7 profiles in June to compare with our five-year-mean simulation in the same month. In contrast to Liu et al. (1984), this set of data provide information about radon distribution over the offshore 
(a) Surface radon concentration (DJF)

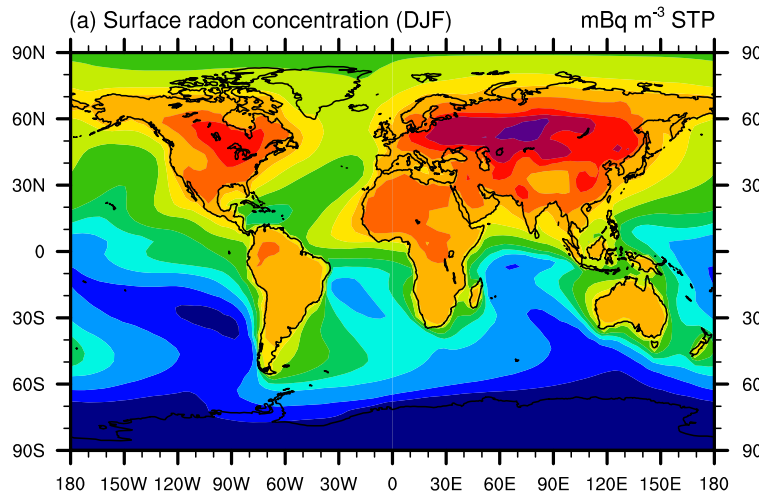

(b) Surface radon concentration (JJA) $\quad \mathrm{mBq} \mathrm{m}^{-3} \mathrm{STP}$

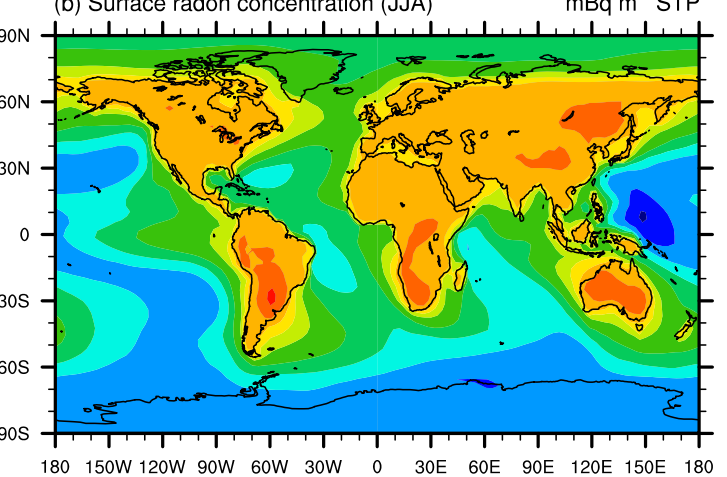

(c) Radon concentration at $300 \mathrm{hPa}$ (DJF) $\quad \mathrm{mBq} \mathrm{m}^{-3} \mathrm{STP}$

(d) Radon concentration at $300 \mathrm{hPa}$ (JJA) $\quad \mathrm{mBq} \mathrm{m}^{-3}$ STP
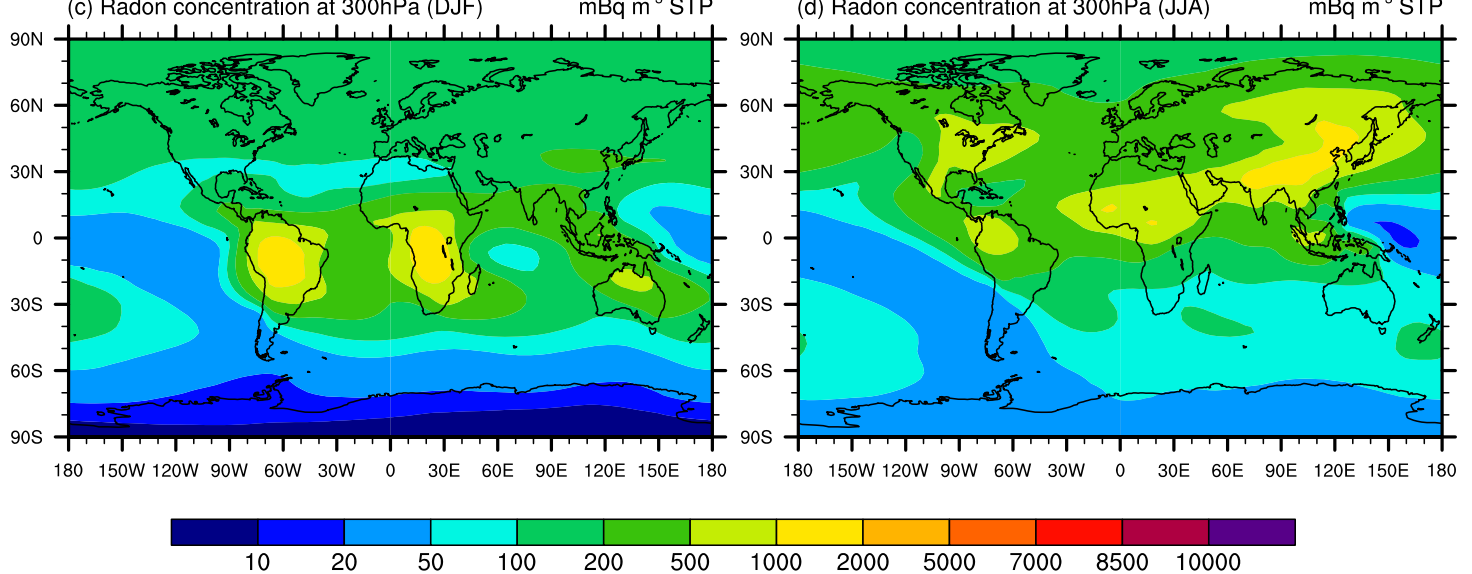

Fig. 5. Geographical distribution of radon concentration simulated with GAMIL using the Zhang-McFarlane-Hack convection scheme. The top panels are results on the lowest model level $(\sigma=0.9925)$; The bottom panels are at $300 \mathrm{hPa}$. The left (right) column shows the DJF (JJA) average of monthly mean.

regions. A similar data set published by Zaucker et al. (1996) was compiled from 9 flights in August 1993 from cities Nova Scotia and New Brunswick on the east coast of Canada to the western North Atlantic Ocean during the North Atlantic Regional Experiment (NARE) Intensive. These measurements covered the vertical range from surface to about $5.5 \mathrm{~km}$.

\section{Simulated global distribution}

Before comparison with in situ observations, we first give an overview of the model's performance by presenting the geographical distribution of the simulated radon concentration on the lowest model level $(\sigma=0.9925)$ and at $300 \mathrm{hPa}$, as well as the zonally averaged pressure-latitude cross sections.

\subsection{Geographical distribution}

The December-January-February (DJF) and June-JulyAugust (JJA) mean surface radon concentrations simulated with the ZMH convection scheme are shown in Fig. 5a and $5 b$, respectively. Here we use the same unit as the measurements, i.e. millibequerel per standard cubic meter at $273.15 \mathrm{~K}$ and $1013.25 \mathrm{hPa}\left(\mathrm{mBq} \mathrm{m}^{-3} \mathrm{STP}\right)$. In this simulation, the highest values appear over the continents, with magnitude of about $10^{4} \mathrm{mBqm}^{-3}$ STP in DJF and $6 \times 10^{3} \mathrm{mBq} \mathrm{m}^{-3} \mathrm{STP}$ in JJA. Radon concentration over the ocean is much lower $\left(10^{1}-10^{3} \mathrm{mBq} \mathrm{m}^{-3} \mathrm{STP}\right)$ due to the absence of emission there. Since the atmospheric stability is generally much higher in winter than in summer, the suppressed upward transport leads to winter concentrations about a factor of 2 to 3 higher than the summer values.

Results at the $300 \mathrm{hPa}$ level are shown in the bottom panels of Fig. 5. High concentrations appear over south America and south Africa due to the deep low-pressure systems in these regions and the associated strong updraft. The large area of high concentration over Asia in JJA is clearly related to the Asian summer monsoon. The largest values exceed $10^{3} \mathrm{mBq} \mathrm{m}^{-3}$ STP.

Changes in the convection parameterization cause evident differences in the radon concentration. Near the earth's surface, values in the convection regions in the $\mathrm{TN}$ run are more than 30\% larger than ZMH (Fig. 6a, b). At $300 \mathrm{hPa}$, the 

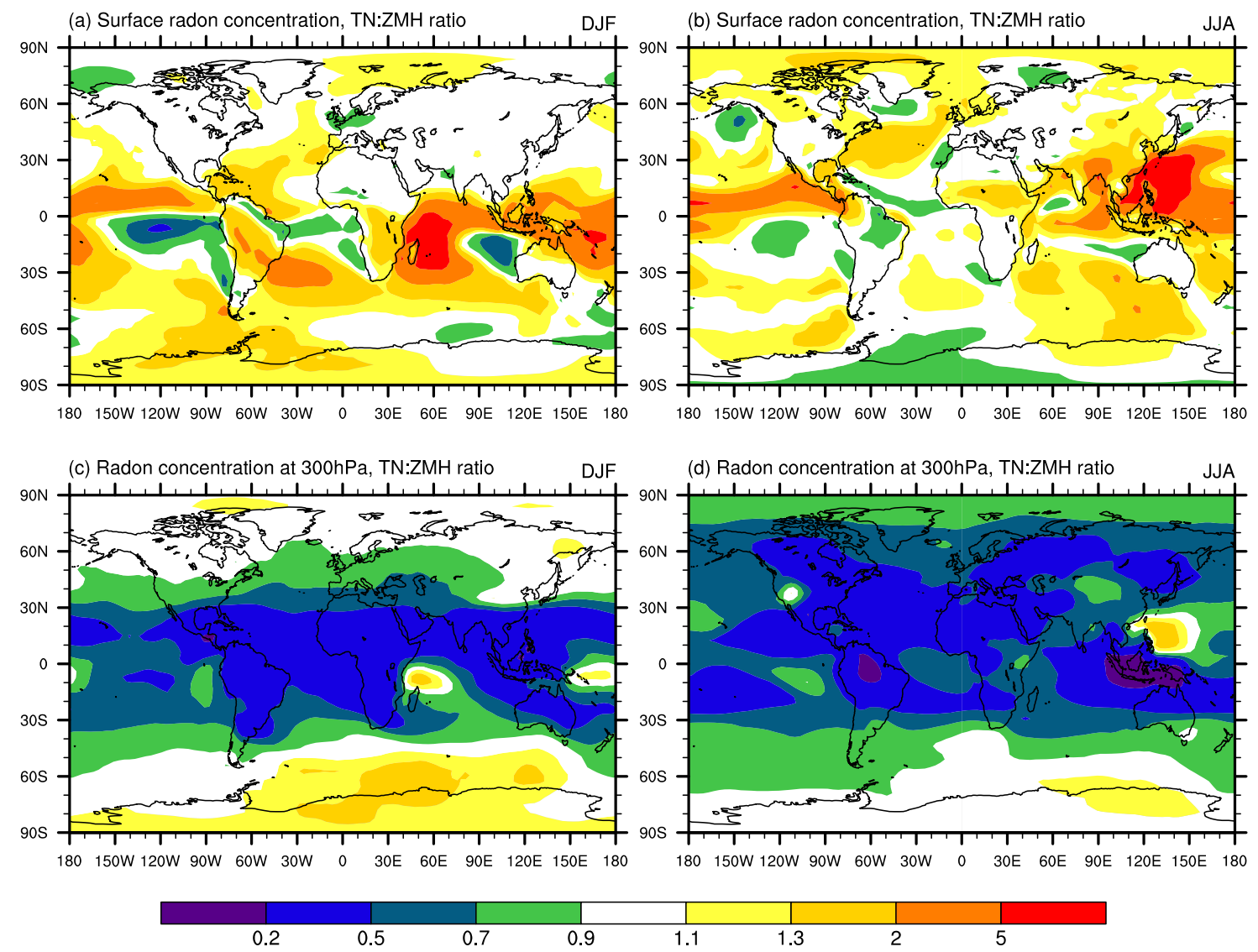

Fig. 6. Differences in the simulated radon concentration between the TN and ZMH simulations. The plotted quantity is the the TN:ZMH ratio. (a) and (b): on the lowest model level $(\sigma=0.9925)$; (c) and (d): at $300 \mathrm{hPa}$.

TN scheme generally produces significantly lower concentrations in the middle and low latitudes (Fig. 6c, d).

\subsection{Zonal mean}

The pressure-latitude cross sections of the zonal mean radon concentration in the ZMH simulation are shown in the top panels of Fig. 7. Here we change the unit to volume mixing ratio $\left(10^{-21} \mathrm{~mol} \mathrm{~mol}^{-1}\right)$ so as to facilitate direct comparison with other publications.

In boreal winter (Fig. 7a), the highest concentrations are located in the northern mid-latitudes and near the earth's surface due to the emission and the atmospheric stability. The lowest values occur over the Antarctica and near model top. In this season the most active convection motions are in the Southern Hemisphere, especially in the South Pacific Convergence Zone (SPCZ). The convective transport leads to a high-concentration region between the equator and $30^{\circ} \mathrm{S}$ throughout the troposphere. From $30^{\circ} \mathrm{S}$ southwards, the concentration decreases very fast on all vertical levels. The contours are almost perpendicular to the earth's surface.
In boreal summer, the strongest convective pumping appears in the Northern Hemisphere. The highest radon concentrations in the upper troposphere shift accordingly to around $25^{\circ} \mathrm{N}$ (Fig. 7b). It should be pointed out that in Fig. 7, no extrapolation was done in remapping the concentration from model grid to pressure levels. This led to missing values on, for example, the $1000 \mathrm{hPa}$ level over land in the tropics. When the zonal mean was calculated, these missing values were ignored and the zonal average represents mainly results over the oceans on the specific level at the specific latitude. This is the reason why we see relatively low concentrations between $30^{\circ} \mathrm{S}$ and $30^{\circ} \mathrm{N}$ below $900 \mathrm{hPa}$ in panel $\mathrm{b}$ and $\mathrm{c}$ of Fig. 7. We have also tried doing the calculation with extrapolation, and got increasing concentration towards the surface in the aforementioned areas which was similar to published results from other models.

Figure $7 \mathrm{~d}$, e and $\mathrm{f}$ are the differences between experiments $\mathrm{TN}$ and ZMH as expressed by the ratio of the zonal mean radon concentration in these experiments. It is clear that in the convection-active regions, the concentration is higher in the lower atmosphere and lower in the upper levels in the 

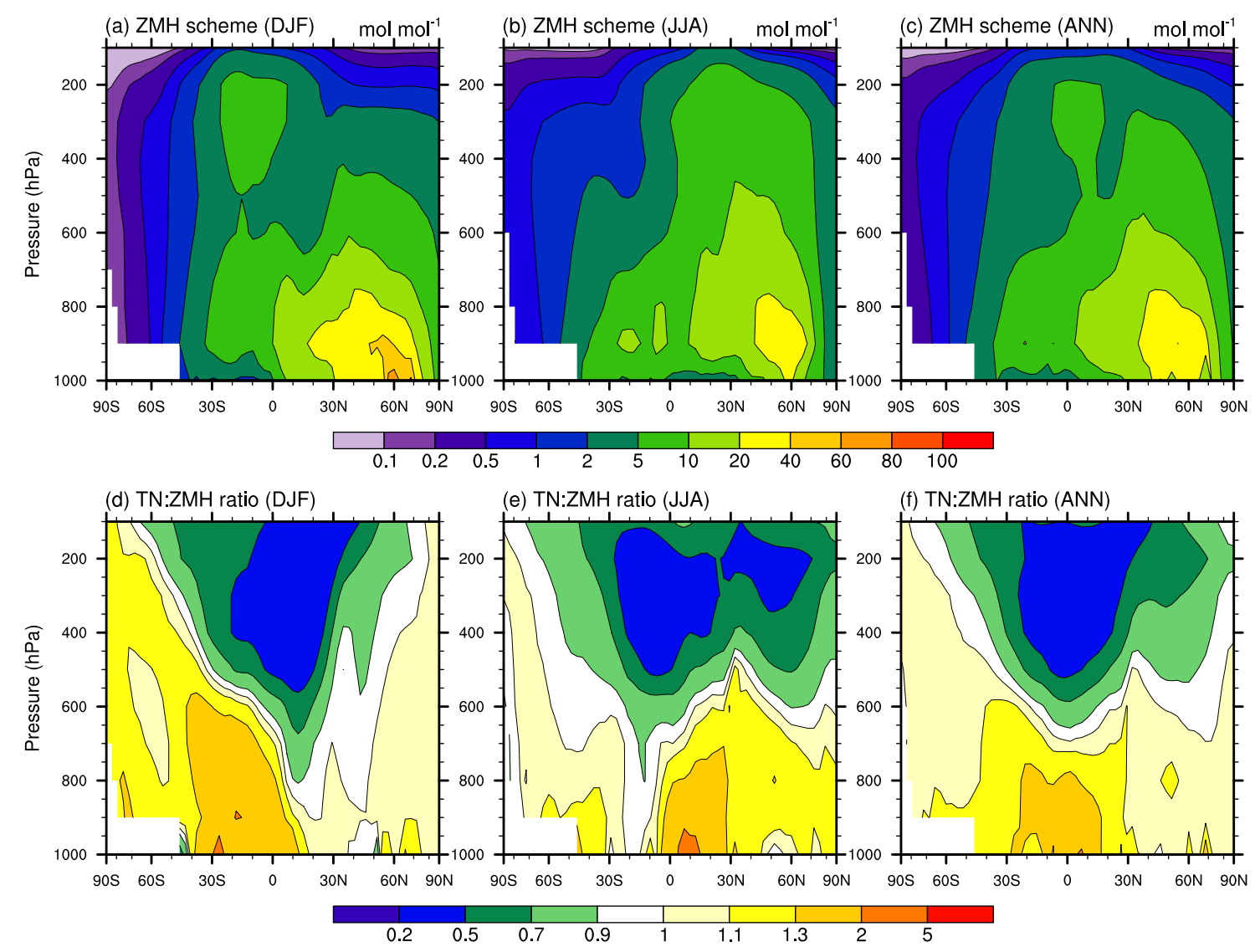

Fig. 7. (a-c): Zonally averaged DJF, JJA and annual mean radon concentration simulated by GAMIL using the ZMH convection scheme. (d-f): Differences between the TN simulation and the $\mathrm{ZMH}$ run as indicated by the TN:ZMH ratio.

TN simulation. The largest difference exceeds a factor of 2. This may possibly be attributed to the fact that the mean upward mass flux in the TN simulation is weaker than in ZMH. Figure 8 shows the cumulus convection mass flux in the two simulations. The original model output on sigma levels are plotted so as to avoid possible artifacts produced by interpolation. Note that the ZMH scheme has two components: the Zhang and McFarlane (1995) parameterization (hereafter ZM95) for penetrative convection, and the Hack (1994) scheme (hereafter Hack94) for the shallow and middle tropospheric convection. The corresponding subroutines in the model are called successively and both contribute to tracer transport. The TN scheme handles all three types of convective activities, but only allows one type to take place each time the scheme is activated. The deep convection mass flux given by the ZM95 scheme (Fig. 8g-i) is similar to the total flux in the TN simulation (Fig. 8d-f), both in magnitude and in the characteristic pattern. A feature worth noting is that in the TN run the strongest updraft in the tropics appears between 600 and $800 \mathrm{hPa}$ and decreases fast in the near surface levels. In contrast, the strong updraft $\left(>4 \mathrm{~g} \mathrm{~m}^{-2} \mathrm{~s}^{-1}\right)$ given by the ZM95 scheme extends to the surface. The ver- tical motion resulting from the Hack94 parameterization is characterized by strongest ascending in the near-surface levels over the storm tracks, as well as secondary strong motions in the upper troposphere and tropical lower atmosphere. The comprehensive effect is that the total mass flux given by ZMH is significantly larger, especially at the model lowest levels. ${ }^{3}$ Given that the source of radon resides at the surface, this implies considerably more effective convective pumping towards the higher altitudes in the ZMH simulation.

In the work by Considine et al. (2005), radon transport tests were conducted with and without convective processes in a chemical transport model. The contribution of convective transport to the zonal and annual mean radon distribution was illustrated in their Fig. 12, which showed by and large

\footnotetext{
${ }^{3}$ The dramatic difference between the two simulations is not a peculiar feature of this specific model. The standard CAM (using the ZMH scheme) also shows relatively strong updraft in the upper troposphere, although not as prominent as here; As for the TN parameterization, convective mass flux similar to the lower panels in Fig. 8 has been observed in previous studies when the Tiedtke scheme was implemented in the CAM model (X.-L. Song, 2008, personal communication).
} 

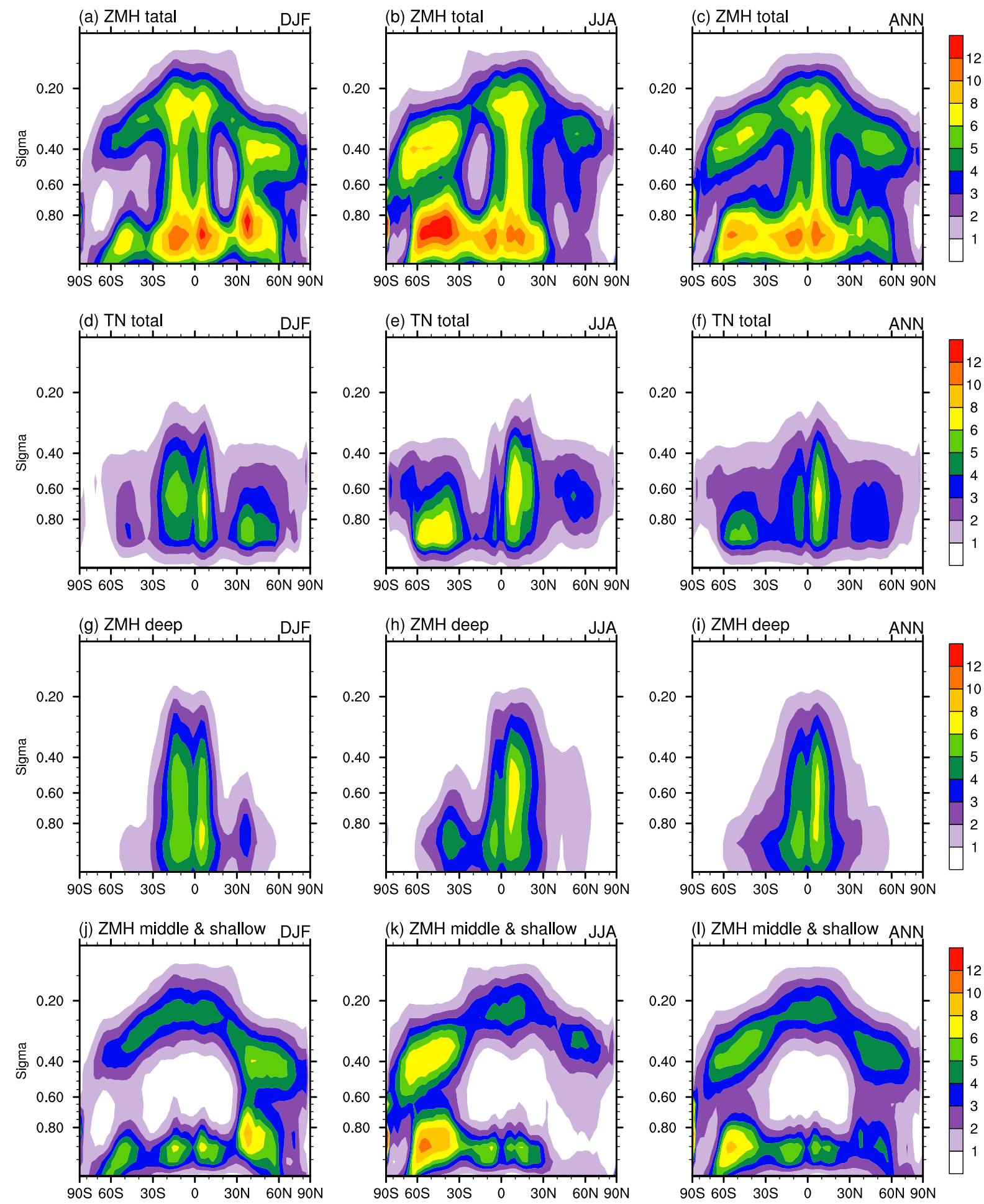

Fig. 8. Zonally averaged DJF, JJA and annual mean net convective mass flux (unit: $\mathrm{g} \mathrm{m}^{-2} \mathrm{~s}^{-1}$ ). The first and second rows are the total convective mass flux simulated with the Zhang-McFarlane-Hack (ZMH) parameterization scheme and the Tiedtke-Nordeng (TN) scheme, respectively. The third row shows the contribution from deep convection in the ZMH simulation. The last row shows the mass flux associated with the middle and shallow convection in the $\mathrm{ZMH}$ simulaiton. 
the same pattern as in Fig. $7 \mathrm{f}$ here. Note that in their control experiments, the convection-related variables (vertical mass flux, entrainment and detrainment rates) were taken from the meteorological data driving the CTM, therefore their estimate was in fact the direct effect of convection on radon distribution. In our GCM, change of convection scheme also affects the transport process by indirectly modifying the general circulation. However, similarity between our results and theirs confirms that the differences we see in Fig. 7 are mainly due to the direct effect of convective transport.

\subsection{Comparison with other models}

Results of the radon transport test from many other models are available in the literature. Figure 5 and 7 here can be compared with, e.g., Figs. 5 and 6 in Jacob et al. (1997), Figs. 1 and 2 in Dentener et al. (1999) and Fig. 5 in Reithmeier and Sausen (2002). From the intercomparison, it is clear that the two versions of the GAMIL model with different convection parameterizations both behave reasonably in large scale transport of passive tracer. The differences detected above are well within the range of inter-model discrepancies. Thus we can not yet conclude which version is better. In the next section radon concentration measurements are used for more detailed comparison.

\section{Comparison with surface measurements}

In order to evaluate the simulated surface radon concentration with respect to in situ measurements, model output is linearly interpolated to the location of the observations. Comparison of the monthly mean concentration at 18 sites is summarized in Fig. 9, which shows a good agreement on the whole. Taking all months at all the 18 sites into account (Fig. 9a), the correlation coefficient between simulation and observation is $0.87(0.85)$ in the $\mathrm{ZMH}(\mathrm{TN})$ run. Out of a total of 213 samples $(12 \times 18$, three samples missing, see Figs. 10f and 13f), $78.7 \%$ (74.1\%) in the ZMH (TN) experiment agree within a factor of 2 with the measurements. Results in summer and in winter (Fig. 9b, c) are of similar quality. Regarding different types of sites (Fig. 9d-f), it can be clearly seen that locations over the oceans (i.e. the remote islands) are characterized by much lower concentrations than the other sites. In panel (e) a cluster of points with measured concentration around $6 \times 10^{2} \mathrm{mBq} \mathrm{m}^{-3}$ STP indicates slight overestimate in both simulations. These points are in fact from a single site (Mace Head), for which detailed discussions are deferred till later.

From Fig. 9 it is difficult to tell any concrete difference between results obtained with different convection schemes. In the following subsections we take a closer look at the monthly mean results at each single location. The continental, oceanic and costal sites are analyzed separately.

\subsection{Continental sites}

The simulated and observed monthly mean radon concentrations at six continental sites are shown in Fig. 10. Variance of the observations within a month is also indicated in the figure when the information is available.

The continental sites are characterized by high surface concentrations of $10^{3}-10^{4} \mathrm{mBq} \mathrm{m}^{-3}$ STP. For Fig. 10a (Beijing, $116^{\circ} 12^{\prime} \mathrm{E}, 39^{\circ} 36^{\prime} \mathrm{N}$ ) we need to point out that the monthly mean indicated by full circles was measured on the fourth floor of a building ( $15 \mathrm{~m}$ above the ground), which has been found to have a much higher annual mean than other observations. The merit of this data set is that it shows the seasonal variation. When it is used for model validation, a potential systematic difference due to the coarse resolution of our global GCM needs to be taken into account. The annual mean reported by Jin et al. (1998) at another location in Beijing (indicated by the solid line in Fig. 10a) and the average of 15 sites in the same city given in Cheng et al. (2002) (the dashed straight line in Fig. 10a) are possibly better references for the annual mean in a global model. With these facts in mind, we can say that the simulations at Beijing agree well with the reality in both the annual mean and the seasonal variation. The two runs with different convection schemes are almost identical, except for slightly higher concentration given by the TN scheme in the summer/autumn months (June to September). The concentration at Socorro $\left(106^{\circ} 54^{\prime} \mathrm{W}, 34^{\circ} 06^{\prime} \mathrm{N}\right.$, Fig. 10b) shows features similar to Beijing. At these mid-latitude locations, the GCM is able to capture the strong seasonal contrast in wind direction and the changes in boundary layer depth. The simulations are therefore quite good.

Cincinnati $\left(84^{\circ} 30^{\prime} \mathrm{W}, 39^{\circ} 08^{\prime} \mathrm{N}\right)$ is also a mid-latitude site but located within a climatic transition zone between the humid subtropical climate and the humid continental climate. Radon concentrations are clearly overestimated in winter and spring in both simulations (Fig. 10c). The same problem has been reported by Reithmeier and Sausen (2002) (see the bottom left panel of Fig. 7 therein), who attributed the discrepancy to the simplified radon emission in the experiment (i.e. the constant emission rate over land). Their explanation was that frost and snow cover in winter and increased soil moisture in spring could reduce the emission flux. Apart from this, negative temperature biases in boreal winter in the GAMIL model over central and northern part of USA and the overly stable boundary layer can also be a reason for the simulated high concentration.

Observations at station Para $\left(55^{\circ} \mathrm{W}, 2^{\circ} 54^{\prime} \mathrm{S}\right.$, Fig. 10d) are obtained in the Tapajos National Forest in the northern part of Brazil. Martens et al. (2004) reported radon data collected on a tower in this region including measurements within and above the forest canopy (ranging from $0.3 \mathrm{~m}$ to $61 \mathrm{~m}$ above the ground level). Since radon concentration within the canopy is quite high due to lack of turbulent mixing and the canopy layer is not resolvable in our model, average 

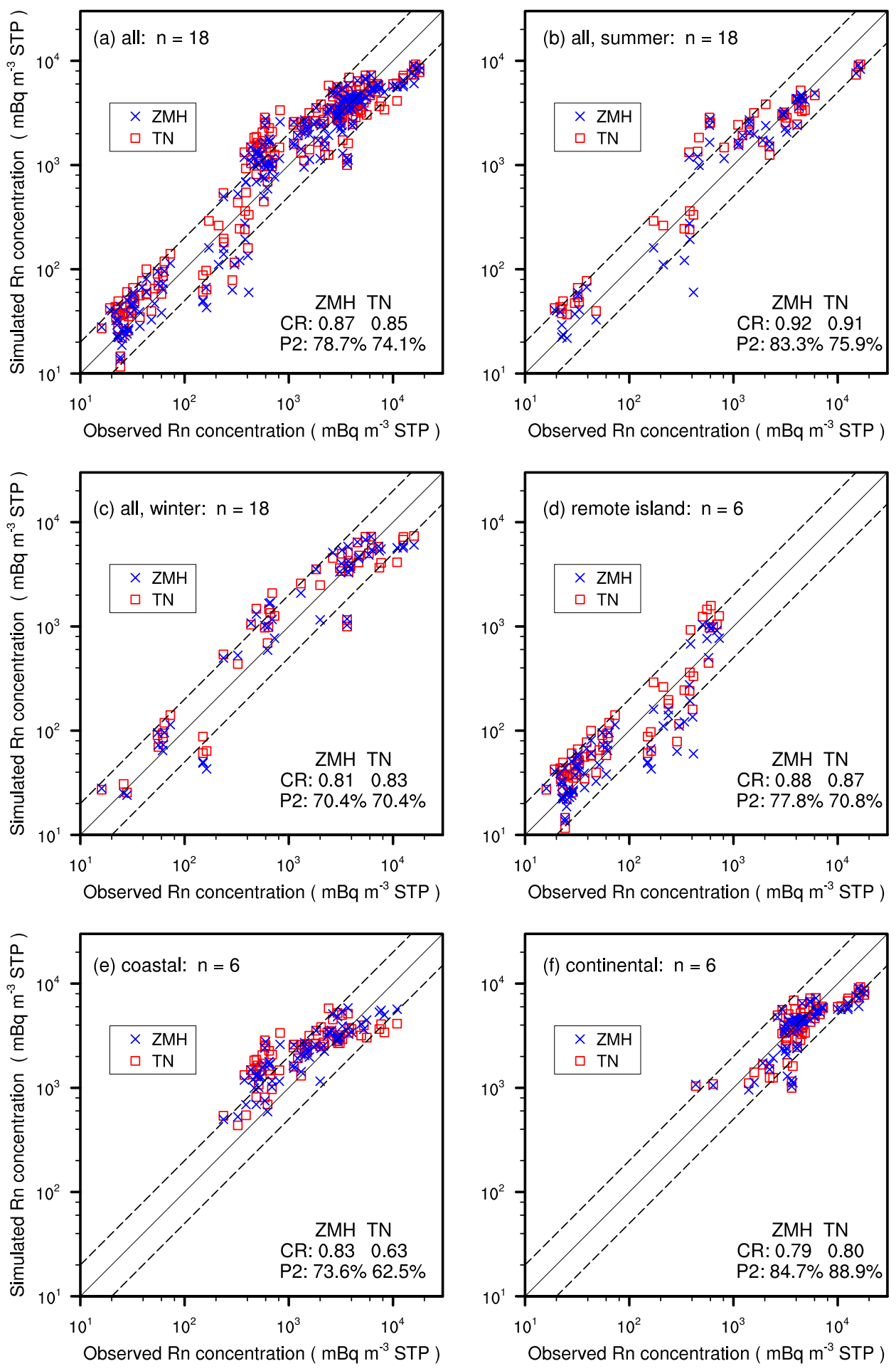

Fig. 9. Scatter plot of the simulated and measured monthly mean surface radon concentration of (a) all samples at all the 18 sites, (b) summer samples (JJA in the Northern Hemisphere, DJF in the Southern Hemisphere) at all the 18 sites, (c) winter samples (DJF in the Northern Hemisphere, JJA in the Southern Hemisphere) at all the 18 sites, (d) all samples at 6 remote island sites, (e) all samples at 6 coastal sites, and (f) all samples at 6 continental sites. Results obtained using the ZMH and TN convection scheme are indicated by open circles and crosses, respectively. The dashed lines indicate the range within a factor of 2 of the measurements. Also shown in each panel are the percentage of samples within this range (the $\mathrm{P} 2$ values) and the correlation coefficients between simulation and observation (the $\mathrm{CR}$ values). 

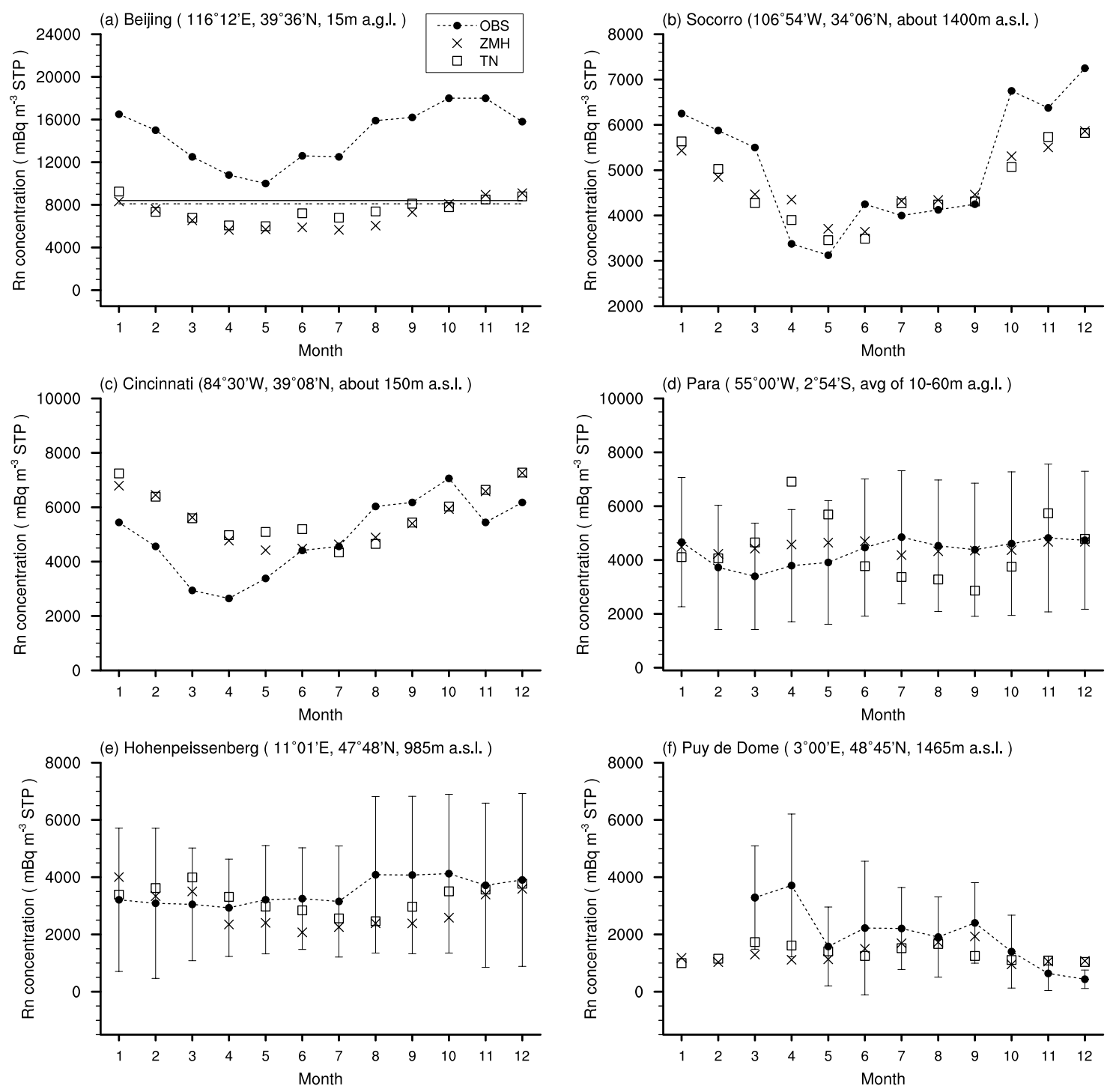

Fig. 10. Observed and simulated monthly mean surface radon concentration at six continental sites. Bars associated with measurements in some panels indicate variance of all the samples (e.g. hourly or 6-h data) within each month. The solid and dashed lines in panel (a) indicate two additional measurements of the annual mean. The abbreviation "a.g.l." in the titles stands for "above ground level"; "a.s.l." stands for "above sea level".

concentration at four altitudes above the $30 \mathrm{~m}$ level $(32.0 \mathrm{~m}$, $37.0 \mathrm{~m}, 47.2 \mathrm{~m}$ and $61.0 \mathrm{~m}$ ) are used in this study. Para station has a typical tropical rainforest climate characterized by small variations in the atmospheric state throughout the year. Consequently the observed monthly mean radon concentration shows much smaller fluctuations compared to the variance calculated from hourly data in each month (Fig. 10d). The ZMH simulation agrees with the observation well except for slight positive biases in March, April and May. The TN simulation also gives a correct value of annual mean, but produces a spurious peak in April and a trough around September. Our analysis reveals that the peak is caused by the signif- icantly weaker convective mass flux in the rainy season near the earth's surface at this location (not shown), which is associated with weaker upward transport from the vicinity of the source. The spurious trough from June to October is caused by the easterly wind bias (Fig. 11) which brings too much fresh air from the Atlantic Ocean and dilutes the radon-rich air over land.

Hohenpeissenberg in Germany (Fig. 10e) is a challenging site for GCMs to simulate because of the orography. The measurements are collected on an isolated mountain rising about $300 \mathrm{~m}$ above the surrounding area. At this type of sites, the surface radon concentration depends strongly on 


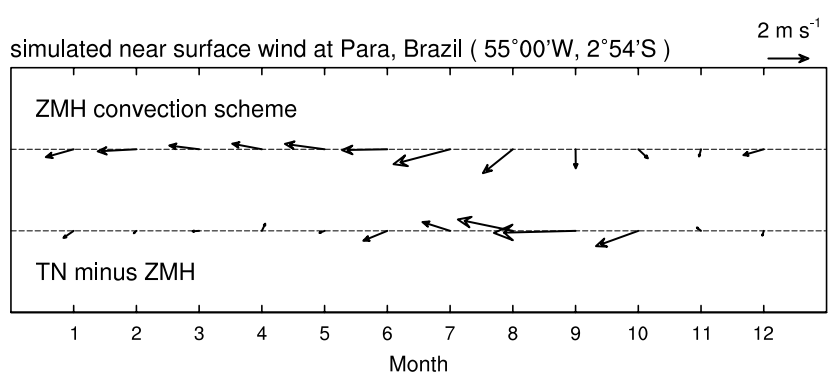

Fig. 11. Monthly mean near-surface wind at Para station simulated with the ZMH convection scheme (top row) and the differences between the TN and ZMH experiments (bottom row).

the status of the boundary layer. In winter and during the night, the boundary layer is usually shallow and the station may possibly level the free atmosphere in the surrounding areas. In case the horizontal wind is weak, radon concentration at the station is mainly affected by the local emission and high values will be recorded; When strong wind comes from the neighboring free atmosphere, horizontal transport will lower the local concentration significantly. In summer and during the day when the atmosphere is relatively unstable, vertical transport to higher altitude is strong, resulting moderate local concentrations. Consequently observations at this kind of stations are typically characterized by small seasonal variation, as we can see in Fig. 10e. However, the fine orographical feature at Hohenpeissenberg is not resolvable at all in a GCM with approximately $300 \mathrm{~km}$ horizontal resolution. Given this fact, results at this site can be regarded as quantitatively correct in the sense of a similar level of seasonal variation and the small bias in the annual mean.

Puy de Dome is also difficult to simulate because it is located on the second highest peak of the Auvergne Mountains. For this station, only ten months of data in a single year (March to December 2002) are available (Fig. 10f). Our simulations show a tendency of negative bias on the whole. This may be due to the fact that orography in the model is much smoother than reality, and the location of the site $(1465 \mathrm{~m}$ above sea level) is therefore farther from the source at surface in the numerical model .

\subsection{Oceanic sites}

Comparison between the observations and simulations on remote islands are presented in Fig. 12. (Station Dumont d'Urville on the coast of Antarctica is also sorted in this group because our experiments assume no emission from Antarctica.) Since these oceanic sites are mainly affected by large scale transport instead of immediate emission and local circulation, a better simulation of the seasonal cycle is expected, which is indeed the case in our results.
Amsterdam Island $\left(77^{\circ} 32^{\prime} \mathrm{E}, 37^{\circ} 47^{\prime} \mathrm{S}\right)$ in the South Indian Ocean is a location for monitoring the background radon concentration. Measurements have been obtained as part of the French Trace Gas Monitoring Program (RAMCES) coordinated by the Laboratory of Sciences of the Climate and the Environment of the Institut Pierre-Simon Laplace (IPSL) (Ramonet et al., 2003). Used in this study is a data set of 20 years $(1981,1983-2001$; No measurement available in 1982). The observed maximum and minimum of monthly means are about $60 \mathrm{mBq} \mathrm{m}^{-3}$ STP and $20 \mathrm{mBq} \mathrm{m}^{-3}$ STP, respectively (Fig. 12a). Records show that during radonic storms, instantaneous concentration can reach $400 \mathrm{mBq}$ $\mathrm{m}^{-3}$ STP and in some years even $700 \mathrm{mBq} \mathrm{m}^{-3}$ STP (Ramonet et al., 2003), implying considerable interannual variability. Considering that our experiments are driven by climatological SST and proceed only five years, the ZMH simulation in fact agrees well with the observation.

Crozet $\left(51^{\circ} 51^{\prime} \mathrm{E}, 46^{\circ} 27^{\prime} \mathrm{S}\right)$ and Kerguelen $\left(70^{\circ} 18^{\prime} \mathrm{E}\right.$, $49^{\circ} 18^{\prime} \mathrm{S}$ ) are also located in the South Indian Ocean but at higher latitudes and lie in the storm track. The validation data in Fig. 12b, c are measurements in the year 1993 from Dentener et al. (1999). Both the ZMH and TN simulations can reproduce the one-cycle-per-year feature at these sites with highest concentration in winter months. However, overestimation is easily detectable. Since there is no local emission, the bias can only be attributed to long range transport. At these sites, wind blows almost continuously from the west throughout the year. The 6-h model output indicates that radon-rich air mass reaching Crozet and Kerguelen originates mainly from the southern part of South America and Africa, which is consistent with earlier studies of Heimann et al. (1990), Mahowald et al. (1997) and Dentener et al. (1999). Dentener et al. (1999) pointed out that positive bias in radon emission over South America in the winter months due to treating frozen soil as non-frozen might be the reason for the aforementioned error at Crozet and Kerguelen. Therefore biases at these two sites should not be considered as defect of numerical models but limitations in the experimental design.

As for the effect of different convection schemes, the three site discussed above exhibit a similar feature: radon concentration in May to July in the TN simulation is higher than ZMH. The discrepancy is especially large at Amsterdam Island. Recall that the most substantial differences in climate state cause by changes in the convection scheme appear during the summer monsoon months over India, East China and the West Pacific. Since the Asian-Australian monsoon is a planet scale phenomenon, circulation in the South Indian Ocean is inevitably affected. We have looked into the surface wind difference and seen that in the TN simulation there is northwest wind anomaly towards these islands from southeast Africa (not shown). Similar anomalies also exist in December and January for Amsterdam Island, although not as significant for the other two sites. The resulting differences in horizontal transport explains the different radon concentrations in the two simulations. 

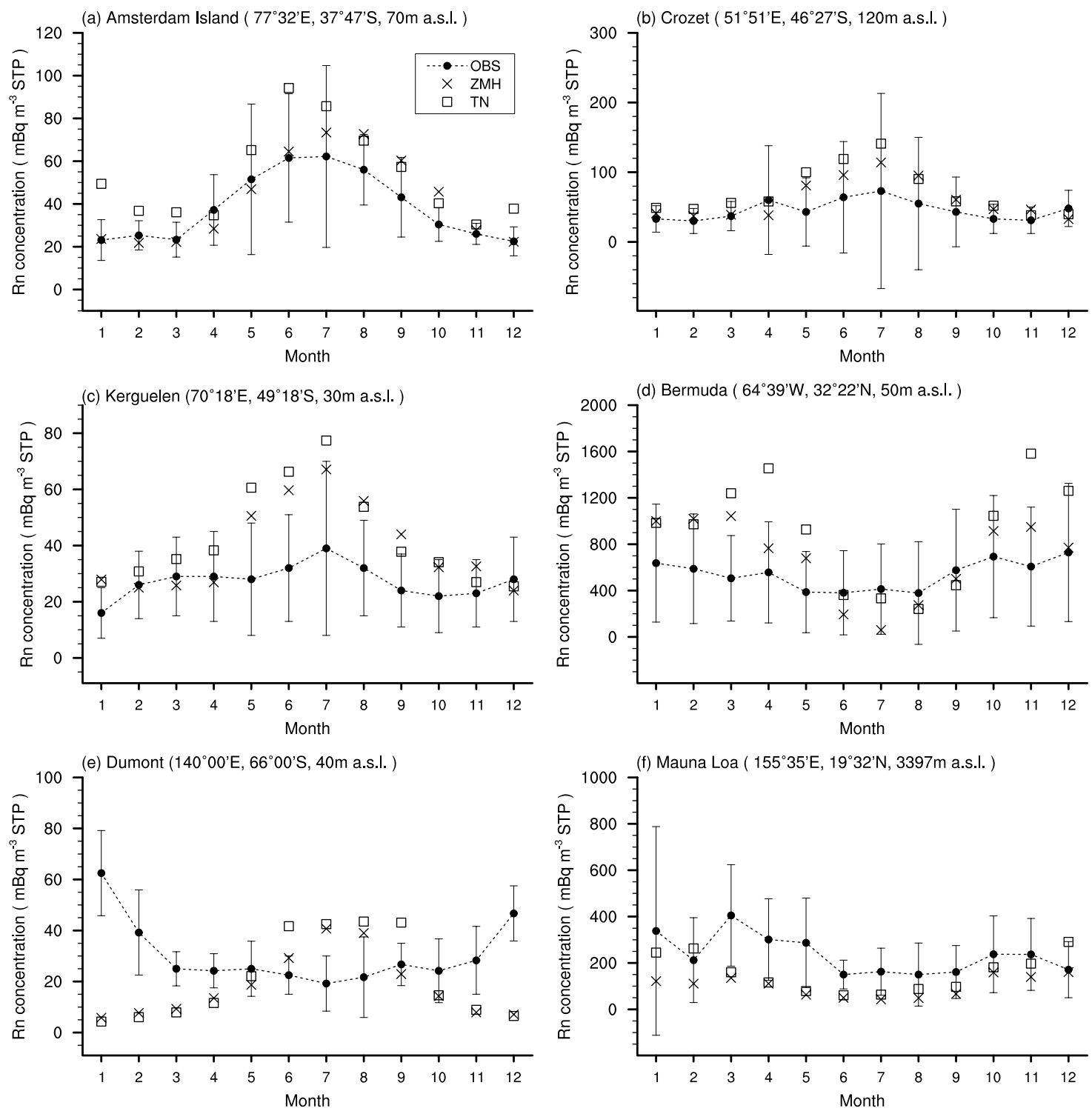

Fig. 12. As in Fig. 10 but for the remote island (i.e. oceanic) sites.

Figure 12d shows the results at Bermuda islands $\left(64^{\circ} 39^{\prime} \mathrm{W}, 32^{\circ} 22^{\prime} \mathrm{N}\right)$. Both simulations are qualitatively correct in terms of the order of magnitude, but show some discrepancies in the seasonal variation as compared to observation. From the sea level pressure and surface wind fields it is clear that in summer the Azores high is strong and located over the subtropical North Atlantic. The air reaching Bermuda comes mainly from the eastern part of the North Atlantic Ocean. Radon concentration at the observatory is therefore low. This feature is well reproduced in our model. However, in winter the Bermuda Islands are strongly affected by the radon-rich air from the North American Continent and the westerly wind is overestimated in the simulations. This explains the relatively large positive bias from late autumn to spring in Fig. 12d.

Dumont d'Urville $\left(140^{\circ} \mathrm{E}, 66^{\circ} \mathrm{S}\right)$ is an interesting station at which the simulations have an annual cycle similar to the three sites already discussed in this subsection, but the observation tells exactly an opposite story (Fig. 12e). The positive biases in June to September are not difficult to explain after the discussions about the 3 Southern Ocean stations above, although the major origin of radon is South America in this case(not shown). As for the summer months, the observed high concentration may be due to local emission from the ice-free coastal area of Antarctica where a constant zero emission is assumed in the experiments. The case of 

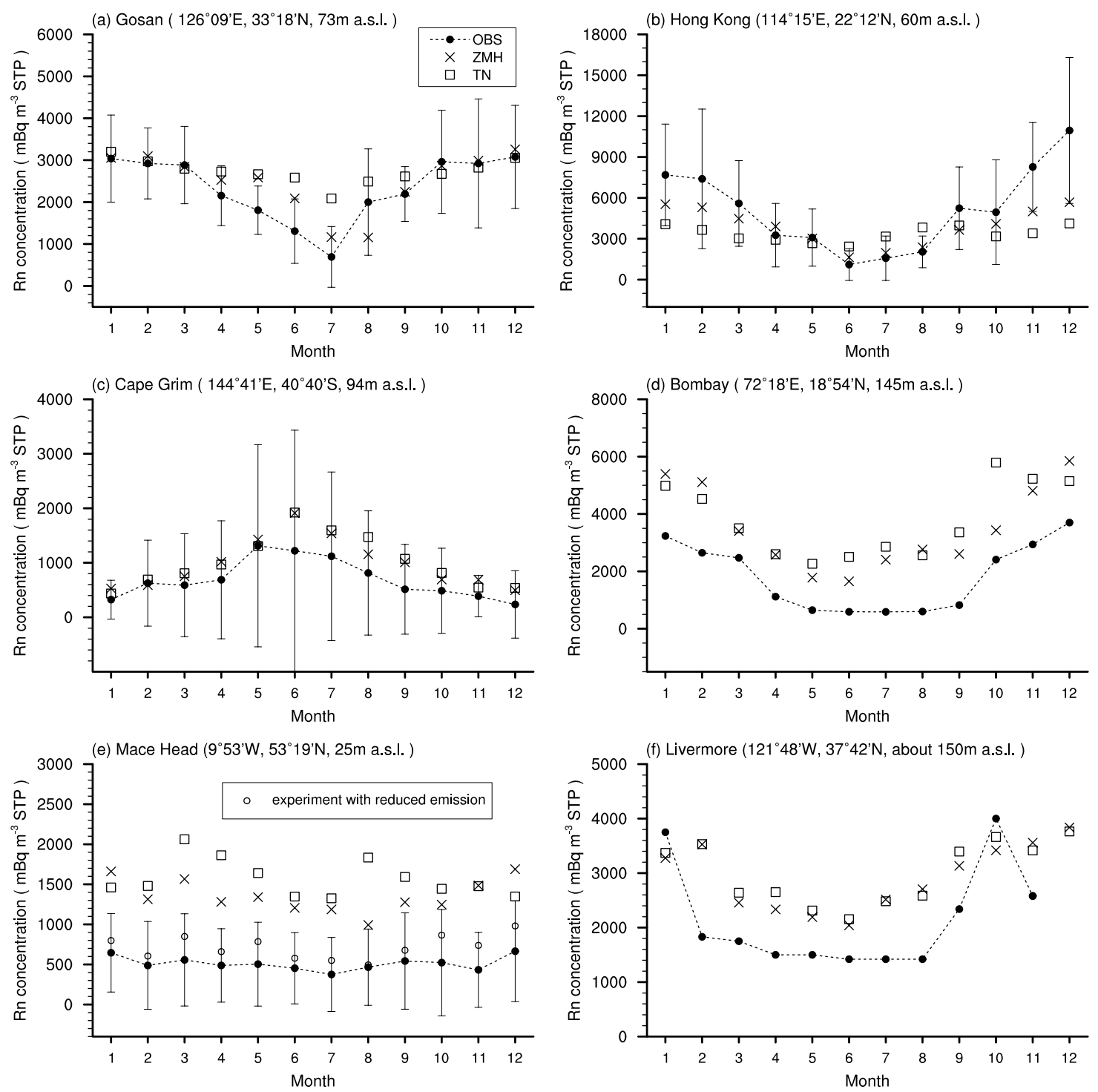

Fig. 13. As in Fig. 10 but for the coastal sites.

Mauna Loa (Fig. 12f) is in some sense similar: The Hawaii islands are sufficiently large to produce non-negligible local radon emission in reality, but still too small to be resolved by the GCM. The incorrect source information is responsible for the systematically low concentration at Mauna Loa station.

\subsection{Coastal sites and East Asia cities}

Figure 13 shows the monthly mean surface radon concentrations at six coastal sites. In reality these are locations on the coast experiencing systematic changes in wind direction throughout a year; In the numerical model, the grid cells in which the observatories are located are recognized as ocean (i.e. no emission), but there is at least one neighboring cell categorized as land at each site. The measurements were

obtained at the transition between large continents and the oceans, thus a correct annual cycle in radon concentration simulation depends mainly on realistic representation of the seasonal wind change, while exact match in each month also relies on detailed features of the circulation in a relatively small region surrounding the site.

Gosan $\left(126^{\circ} 12^{\prime} \mathrm{E}, 33^{\circ} 18^{\prime} \mathrm{N}\right)$ and Hong Kong $\left(114^{\circ} 18^{\prime} \mathrm{E}\right.$, $22^{\circ} 12^{\prime} \mathrm{N}$ ) are typical sites in East Asia, a monsoon region that is not very well handled in many models mainly due to the topography in the west. As can be seen in Fig. 13a and b, seasonal cycle at these two sites are quite realistically reproduced by the GAMIL model. Additional comparison of the annual mean radon concentration at ten Chinese cities with the measurements reported in Jin et al. (1998) is presented 
in Fig. 14. Note that an earlier study by Schery and Wasiolek (1998) has revealed that South China is characterized by very high emissions in reality (equivalent to 1.5 to more than 2.6 atoms $\mathrm{cm}^{-2} \mathrm{~s}^{-1}$, see Fig. 5 therein). Furthermore the city Gaoxiong (also known as Kaohsiung) in our experiments is actually an oceanic site without local emission. These facts can explain the considerable underestimate at the last four sites in Fig. 14. That being considered, it is fair to say that Fig. 14 also confirms the model's relatively good performance in East Asia.

Results at Cape Grim $\left(144^{\circ} 41^{\prime} \mathrm{E}, 40^{\circ} 40^{\prime} \mathrm{S}\right)$ are also satisfactory (Fig. 13c), while positive biases occur at Bombay on the Indian Peninsula (Fig. 13d) and Livermore on the west coast of North America (Fig. 13f). The former may result from the westerly wind bias that brings an excess of radonrich air from the continent (not shown). As for Livermore, the 11-month data with large variance (e.g. in October) seem not yet sufficient for a quantitative comparison.

Positive biases also appear at Mace Head in Ireland as compared to the 7-year-mean observation, which can be attributed to the overestimated emission. According to Schery and Wasiolek (1998), West and North Europe are characterized by relatively low emissions. An additional experiment has be conducted using the ZMH convection scheme, but with the emission decreasing linearly from 1 atom $\mathrm{cm}^{-2} \mathrm{~s}^{-1}$ at $30^{\circ} \mathrm{N}$ to 1 atom $\mathrm{cm}^{-2} \mathrm{~s}^{-1}$ at $70^{\circ} \mathrm{N}$ as proposed by Conen and Robertson (2002). The recalculated radon concentrations are indicated by open circles in Fig. 13e which show an evident improvement.

Comparing the two convection schemes, differences are not evident at the coastal sites in Fig. 13. At the East China city sites the TN scheme gives a slightly higher annual mean concentration.

\section{Comparison of vertical profiles}

In this section we attempt to investigate the sensitivity of radon simulation to convection scheme by looking into the vertical structure. Presented in Fig. 15 are the vertical profiles of radon concentration averaged over different geographic regions. In the tropics (Fig. 15b, e) only the annual means are plotted; In the middle latitudes, winter and summer profiles are given separately.

In contrast to the previous section, distinct differences can be detected between the ZMH and TN simulations. The relatively weak updraft associated with the TN scheme leads to higher concentration near the surface but lower values above $3 \mathrm{~km}$. The differences are most evident in the tropical areas and in summer. On the other hand, the two convection schemes also produce many similar features. For example, the concentration decreases the fastest with height near the earth's surface; it appears to be almost constant despite the increasing altitude from $6 \mathrm{~km}$ to the tropopause in the low latitudes and during summer in middle latitudes, indicating

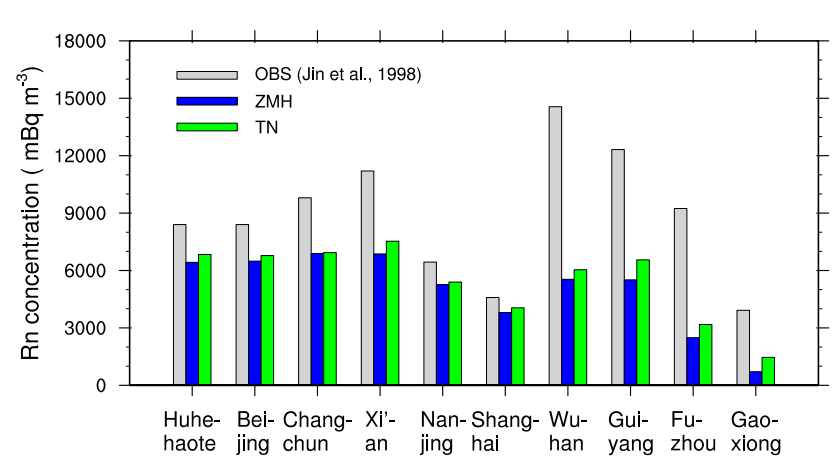

Fig. 14. Observed and simulated annual mean surface radon concentration in ten Chinese cities.

strong vertical transport by cumulus convection. Considerable seasonal changes occur in the middle latitudes. Summer concentrations are higher at almost all altitudes over the continents while the reverse is true in the lower atmosphere over the oceans.

The upper panels in Fig. 16 compare the simulations over the mid-latitude land areas in the Northern Hemisphere with the compilation results of Liu et al. (1984). The latter were obtained by averaging measurements over the United States and eastern Ukraine. In summer (Fig. 16a), the nearly loglinear decrease of radon concentration from the surface to $4 \mathrm{~km}$ is well captured by both convection schemes. The smaller decrease rate between 4 and $8 \mathrm{~km}$ is better represented by the ZMH scheme. In the upper troposphere the again enhanced decrease rate seems to be underestimated by both schemes. The observed winter profile (Fig. 16b) also has the three-sector structure but with even stronger contrasts. The two simulations show less differences than in summer and a smoother change through vertical levels than the observation. Considering the fact that the winter measurements consist of only 7 sites while the model results are computed from all the continental grid points between $30^{\circ} \mathrm{N}$ and $60^{\circ} \mathrm{N}$, the discrepancies are acceptable.

For the offshore regions, radon concentration profiles have been reported by Kritz et al. (1998) obtained near Moffett Field in California, USA, and by Zaucker et al. (1996) near the western coast of Canada. Figure 16c compares a composite of June 1994 profiles from Kritz et al. (1998) with the five-year-mean model results in June averaged from the two coastal cells where the measurements were collected. The error bars (black line) indicate the standard deviation of the measurements. The log-linear decrease till $4 \mathrm{~km}$ and the nearly constant concentration from 4 to $10 \mathrm{~km}$ above the surface are very well represented by the model with both convection schemes. This plot can be compared with Fig. 6 in Considine et al. (2005) where the same measurement was used to validate a CTM driven by three different meteorological data sets. They reported near-surface values which 
(a) $30^{\circ} \mathrm{N}-60^{\circ} \mathrm{N}$, Land

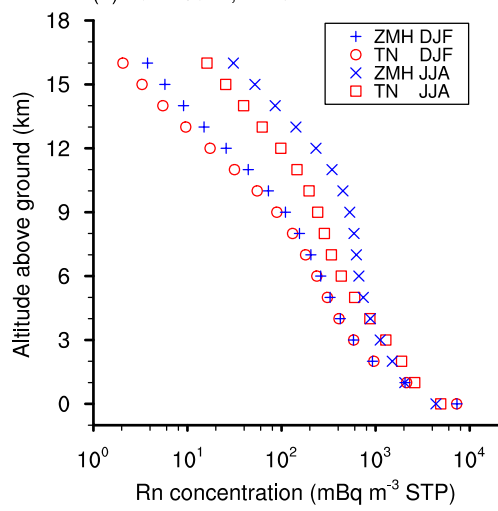

(d) $30^{\circ} \mathrm{N}-60^{\circ} \mathrm{N}$, Ocean

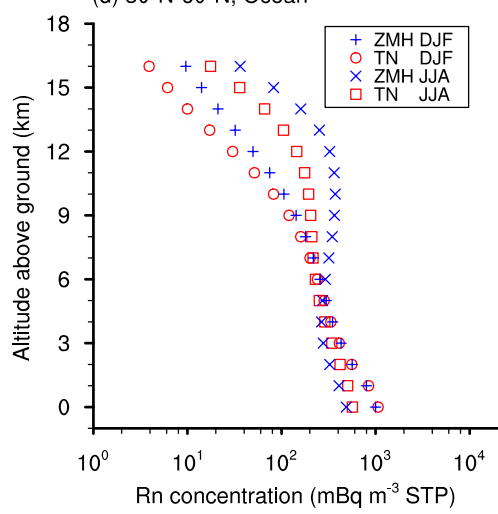

(b) $20^{\circ} \mathrm{S}-20^{\circ} \mathrm{N}$, Land

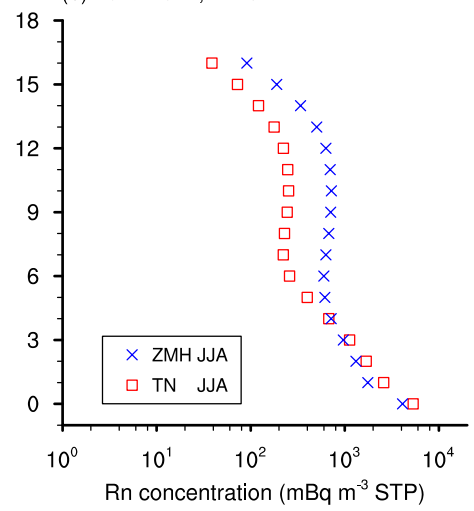

(e) $20^{\circ} \mathrm{S}-20^{\circ} \mathrm{N}$, Ocean

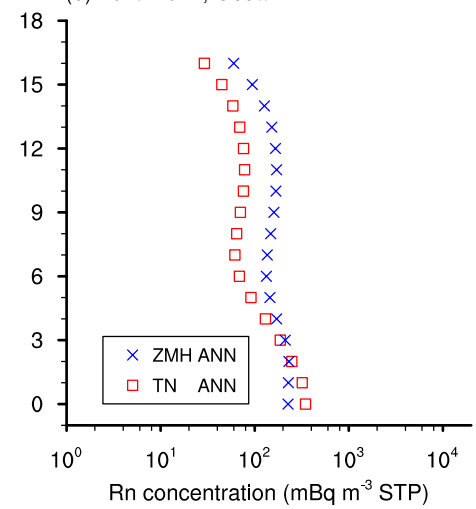

(c) $30^{\circ} \mathrm{S}-60^{\circ} \mathrm{S}$, Land

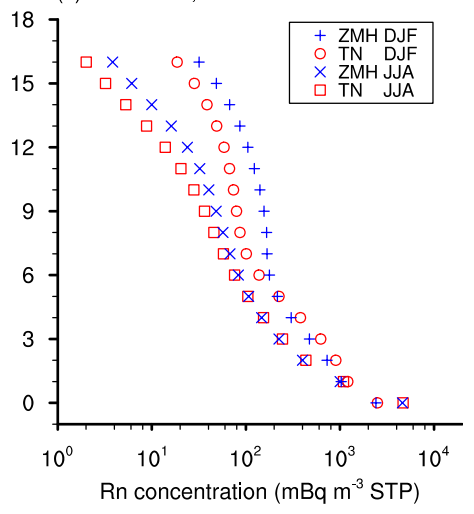

(f) $30^{\circ} \mathrm{S}-60^{\circ} \mathrm{S}$, Ocean

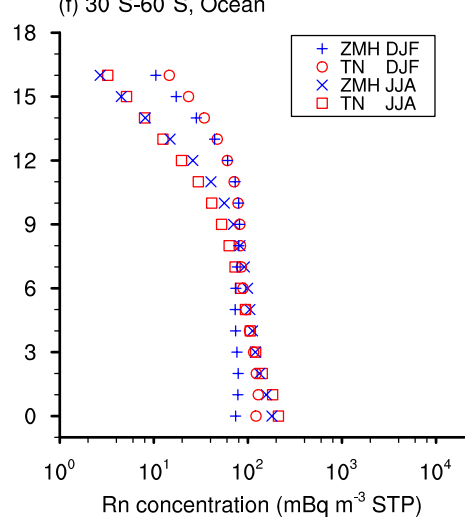

Fig. 15. Vertical profiles of radon concentration simulated with the ZMH and TN convection schemes. Plotted are the averages over different regions as indicated in the title of each panel.

consistently exceeded observations by a factor of 2 to 3 , and attributed the biases to the low resolution $\left(5^{\circ}\right.$ longitudinal) in their study. The horizontal grid in our experiments has only half the grid size $\left(2.8^{\circ}\right)$. In addition, the cells from which the Moffett Field profile is obtained do not have local emissions. These two facts possibly explain the improvement in our simulations.

Figure 16d shows the simulated profiles in August averaged over $41^{\circ}-46^{\circ} \mathrm{N}, 60^{\circ}-70^{\circ} \mathrm{W}$. Here we see again the differences in the upper and lower troposphere due to convective transport. Compared to the composite below $6 \mathrm{~km}$ given in Zaucker et al. (1996), the ZMH scheme gives more realistic results. Although even larger differences are seen at higher altitudes between the two simulations, there is no observation there to help judge which one is better.

\section{Summary and conclusion}

In this study we have carried out the radon $\left({ }^{222} \mathrm{Rn}\right)$ transport test using an atmospheric GCM with a finite-difference dynamical core, the van Leer type FFSL algorithm for radon ad- vection and two different cumulus convection schemes. The purpose was to validate the large scale transport processes in the model and to choose a suitable convection scheme for subsequent studies. Measurements of surface concentration and vertical distribution of radon were collected from literature and used as references in model evaluation.

The simulated radon concentration is reasonable. At a global scale, the spatial distribution is consistent with published results from many other models. Magnitude of the differences caused by changes in the convection scheme is well below the inter-model discrepancies. When compared to measurements, it is found that at the locations where significant seasonal variations are observed in reality, the model can reproduce both the annual mean surface radon concentration and the seasonal cycle quite well. At those sites where the surface concentration is strongly affected by local features such as the boundary layer thickness and fine topography, but shows only small changes through different seasons, the model is able to give a correct magnitude of the annual mean. A unique feature of this study is the detailed analysis in East Asia. Although this is a problematic region in many global models, our simulations compare reasonably well with the 
(a) $30^{\circ} \mathrm{N}-60^{\circ} \mathrm{N}$, Land, Summer (JJA)

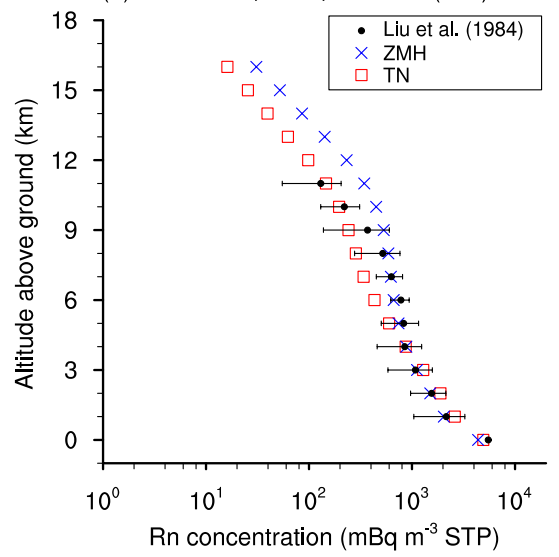

(c) Moffett Field $\left(37^{\circ} 24^{\prime} \mathrm{E}, 27^{\circ} 00^{\prime} \mathrm{N}\right)$

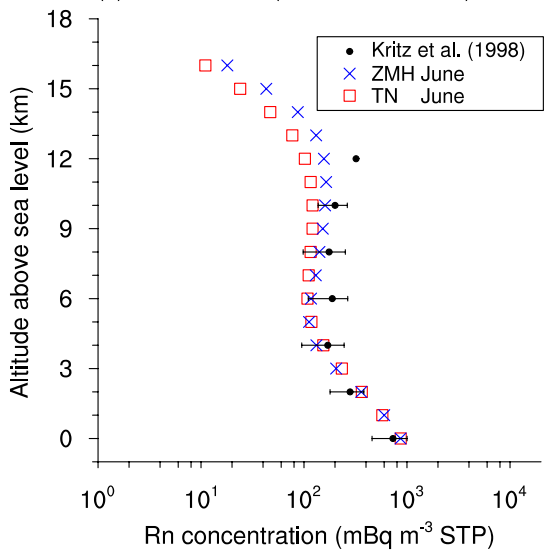

(b) $30^{\circ} \mathrm{N}-60^{\circ} \mathrm{N}$, Land, Winter (DJF)

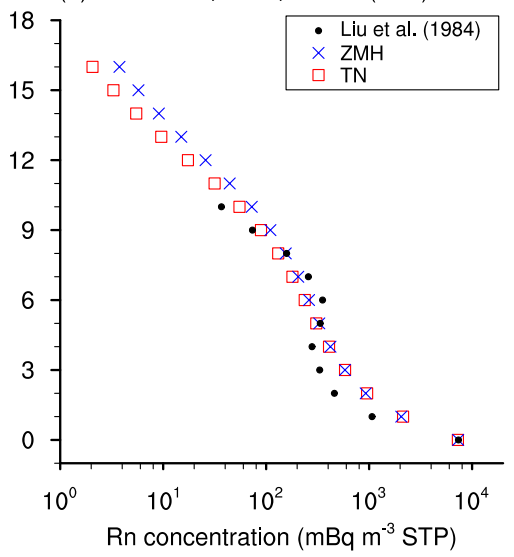

(d) NARE compaign $\left(41^{\circ}-46^{\circ} \mathrm{N}, 60^{\circ}-70^{\circ} \mathrm{W}\right)$

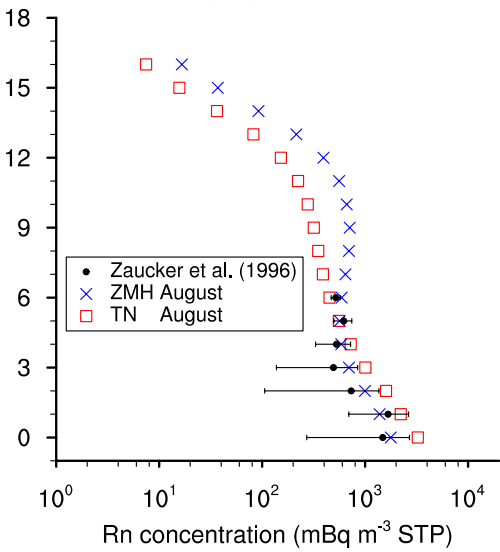

Fig. 16. Comparison of the simulated and observed profiles of radon concentration. The colored marks are model results. The black dots are observations. Error bars (black line) indicate the standard deviation of the measurements.

observations. These results confirm the GAMIL model's ability in large scale transport, which provides a good basis for the future studies on aerosol modelling and atmospheric chemistry.

A special focus of our work is the sensitivity of tracer transport to cumulus convection parameterization. Here we have compared two state-of-the-art convection schemes that are widely used by global models in recent years. The most evident differences between simulations with the $\mathrm{ZMH}$ and $\mathrm{TN}$ schemes are found in the vertical distribution of the tracer. The TN scheme is characterized by a weaker upward transport, especially at the near surface levels, thus results in higher radon concentration in the near-surface levels and lower values in the middle and upper part of the troposphere. This can be clearly seen from the geographical distribution of radon and the vertical profiles at individual sites as well. Despite the earlier findings that the TN scheme leads to evident improvements in this model in precipitation, especially in the Asian monsoon regions, we do not see superior results given by the TN scheme in terms of the surface radon concentration and its temporal variation. Vertical profiles simulated by the ZMH scheme agrees slightly better with the observations in the lower atmosphere. However, the largest differences actually occur above $6 \mathrm{~km}$ and extend till the model top. The concentration calculated in the $\mathrm{ZMH}$ simulation can be twice as high as or even larger than in the TN run. Due to lack of observation at these altitudes, we are not yet able to tell which simulation is more realistic.

The dramatic differences between the two simulations in convective mass flux indicate again the high level of uncertainty associated to the cumulus convection parameterization. When checking the convection-related 4-dimensional model output, we have noticed that the convection activities simulated by the ZMH and TN schemes in the GAMIL model have very distinct temporal and spacial features as well. The exact reason is not yet clear. A thorough investigation of the causes of these differences probably requires detailed comparison of the formulations of these two parameterizations, 
the empirical parameters used, as well as the interaction with the other parts of the AGCM. Further comparison and sensitivity studies have been planned.

Acknowledgements. The authors are grateful to J. Feichter and X.-L. Song for helpful comments and discussions. The radon concentration data at Cape Grim and the three RAMCES sites were kindly provided by W. Zahorowski and M. Ramonet. Suggestions from the two anonymous reviewers helped improve the original manuscript. We acknowledge support from the Chinese Academy of Sciences' International Partnership Creative Group "The Climate System Model Development and Application Studies", the 973 Project Grant 2005CB321703, and the Fund for Innovative Research Groups Grant 40221503. K. Zhang was partially supported by the PhD Student Promotion Project between the Max Planck Society and the Chinese Academy of Sciences. H. Wan is recipient of a fellowship from the ZEIT Foundation "Ebelin and Gerd Bucerius" in Hamburg, Germany.

Edited by: K. Hamilton

\section{References}

Arakawa, A.: The Cumulus Parameterization Problem: Past, Present, and Future, J. Climate, 17, 2493-2525, 2004.

Bechtold, P., Chaboureau, J.-P., Beljaars, A., Betts, A. K., Köhler, M., Miller, M., and Redelsperger, J.-L.: The simulation of the diurnal cycle of convective precipitation over land in a global model, Q. J. Roy. Meteor. Soc., 130, 3119-3137, 2004.

Boville, B. A. and Bretherton, C. S.: Heating and dissipation in the NCAR community atmosphere model, J. Climate, 16, 38773887, 2003.

Cheng, J., Guo, Q., and Ren, T.: Radon levels in China, J. Nucl. Sci. Technol., 39, 695-699, 2002.

Collins, W. D., Hack, J., Boville, B., Williamson, P. R. D. L., Kiehl, J. T., Briegleb, B., McCaa, J. R., Bitz, C., Lin, S.-J., Rood, R. B., Zhang, M., and Dai, Y.: Description of the NCAR Community Atmosphere Model (CAM2)., Ncar technical report, National Center for Atmospheric Research, available at: http://www.ccsm.ucar.edu/models/atm-cam/docs/cam2.0/, 2003.

Conen, F. and Robertson, L. B.: Latitudinal distribution of radon222 flux from continents., Tellus, 54B, 127-133, 2002.

Considine, D. B., Bergmann, D. J., and Liu, H.: Sensitivity of Global Modeling Initiative chemistry and transport model simulations of radon-222 and lead-210 to input meteorological data, Atmos. Chem. Phys., 5, 5325-5372, 2005,

http://www.atmos-chem-phys.net/5/5325/2005/.

Dentener, F., Feichter, J., and Jeuken, A.: Simulation of ${ }^{222}$ Radon using on-line and off-line global models, Tellus B, 51, 573-602, 1999.

Feichter, J. and Crutzen, P. J.: Parameterization of vertical tracer transport due to deep cumulus convection in a global transport model and its evaluation with 222Radon measurements, Tellus B, 42, 100-117, 1990.

Gates, W. L., Boyle, J. S., Covey, C., Dease, C. G., Doutriaux, C. M., Drach, R. S., Fiorino, M., Gleckler, P. J., Hnilo, J. J., Marlais, S. M., Phillips, T. J., Potter, G. L., Santer, B. D., Sperber, K. R., Taylor, K. E., and Williams, D. N.: An Overview of the Results of the Atmospheric Model Intercomparison Project (AMIP I), B. Am. Meteorol. Soc., 80, 29-55, 1999.

Genthon, C. and Armengaud, A.: Radon 222 as a comparative tracer of transport and mixing in two general circulation models of the atmosphere, J. Geophys. Res., 100, 2849-2866, 1995.

Gold, S., Barkhau, H. W., Shleien, B., Kahn, B.: Measurement of naturally occurring radionuclides in air, in: Natural Radiation Environment, edited by: Adams, J. A. S. and Lowder, W. M., Chicago, University of Chicago Press, 1964.

Guelle, W., Balkanski, Y. J., Schulz, M., Dulac, F., and Monfray, P.: Wet deposition in a global size-dependent aerosol transport model. 1. Comparison of a 1 year ${ }^{210} \mathrm{~Pb}$ simulation with ground measurements, J. Geophys. Res., 103, 11 429-11 445, 1998.

Hack, J. J.: Parameterization of moist convection in the National Center for Atmospheric Research Community Climate Model (CCM2), J. Geophys. Res., 99, 5551-5568, 1994.

Heimann, M., Monfray, P., and Polian, G.: Modeling the long-range transport of ${ }^{222} \mathrm{Rn}$ to subantarctic and arctic areas, Tellus B, 42, 83-99, 1990.

Holtslag, A. A. M. and Boville, B. A.: Local versus nonlocal boundary-layer diffusion in a global climate model, J. Climate, 6, 1825-1842, 1993.

Hutter, A. R., Larsen, R. J., Maring, H., and Merrill, J. T.: ${ }^{222}$ Rn at Bermuda and Mauna Loa: Local and Distant Sources, J. Radioanal. Nucl. Ch., 193, 309-318, 1995.

Jacob, D. J., Prather, M. J., and Rasch, P. J.,: Evaluation and intercomparison of global atmospheric transport models using ${ }^{222} \mathrm{Rn}$ and other short-lived tracers, J. Geophys. Res., 102, 5953-5970, 1997.

Jin, Y. I., Iida, T., Wang, Z., Ikebe, Y., and Abe, S.: A subnationwide survey of outdoor and indoor ${ }^{222} \mathrm{Rn}$ concentrations in China by passive Method. Radon and thoron in the human environment, in: Radon and Thorn in the Human Environment, edited by: Katase, A., and Shimo, M., Proceedings of the 7th Tohwa University International Symposium, World Scientific Publishing Co. Pre. Ltd., Singapore, 276-281, 1998.

Kritz, M. A., Rosner, S. W., and Stockwell, D. Z.: Validation of an offline three-dimensional chemical transport model using observed radon profiles -1 . Observations, J. Geophys. Res., 103, 8425-8432, 1998.

Lambert, G., Polian, G., Sanak, J., Ardouin, B., Buisson, A., Jegou, A., and Le Roulley, J.: Cycle du radon et de ses descendants: application à l'étude des échanges troposphère-stratosphère, Ann. Géophys., 38, 497-531, 1982.

Lee, H. N. and Feichter, J.: An intercomparison of wet precipitation scavenging schemes and the emission rates of ${ }^{222} \mathrm{Rn}$ for the simulation of global transport and deposition of ${ }^{210} \mathrm{~Pb}$, J. Geophys. Res., 54, 23 252-23 270, 1995.

Lin, S. J. and Rood, R. B.: Multidimensional flux-form semiLagrangian transport schemes, Mon. Weather Rev., 124, 20462070, 1996.

Lindeken, C. L.: Seasonal variations in the concentration of airborne radon and thoron daughters, USAEC Rep. UCRL-50007, University of California Lawrence Radiation Laboratory, Livermore, CA, 41-43, 1966.

Liu, P., Wang, B., Sperber, K. R., Li, T., and Meehl, G. A.: MJO in the NCAR CAM2 with the Tiedtke Convective Scheme, J. Climate, 18, 3007-3020, 2005.

Liu, S. C., McAfee, J. R., and Cicerone, R. J.: Radon 222 and tro- 
pospheric vertical transport, J. Geophys. Res., 89, 7291-7297, 1984.

Mahowald, N. M., Rasch, P., and Prinn, R. G.: Cumulus parameterizations in chemical transport models, J. Geophys. Res., 100, $26173-26189,1995$.

Mahowald, N. M., Rasch, P. J., Eaton, B. E., Whittlestone, S., and Prinn, R. G.: Transport of ${ }^{222}$ radon to the remote troposphere using the Model of Atmospheric Transport and Chemistry and assimilated winds from ECMWF and the National Center for Environmental Prediction/NCAR, J. Geophys. Res., 102, 28 139$28151,1997$.

Martens, C. S., Shay, T. J., Mendlovitz, H. P., Matross, D. M., Saleska, S. R., Wofsy, S. C., Menton, W. S. W., Moura, M. C., Crill, P. M., De Moraes, O. L. L., and Lima, R. L.: Radon fluxes in tropical forest ecosystems of Brazilian Amazonia: night-time $\mathrm{CO}_{2}$ net ecosystem exchange derived from radon and eddy covariance methods, Global Change Biol., 10, 618-629, 2004.

Mishra, U. C., Rangarajan, C., and Eapen, C. D.: Natural radioactivity of the atmosphere over the Indian land mass, inside deep mines, and over adjoining oceans, Natural Radiation Environment III. US Department of Energy, Special Symposium Series 51, CONF 780422, US Department of Energy, Washington, DC, 327-346, 1980.

Nordeng, T. E.: Extended versions of the convective parametrization scheme at ECMWF and their impact on the mean and transient activity of the model in the tropics, ECMWF Research Department, Technical Momorandum 206, European Centre for Medium-Range Weather Forecast, Reading, UK, 618-629, 1994.

Olivié, D. J. L., van Velthoven, P. F. J., and Beljaars, A. C. M.: Evaluation of off-line diagnosed vertical diffusion coefficients from ERA-40 with ${ }^{222}$ Rn simulations, Atmos. Chem. Phys., 4, 23132336, 2004 http://www.atmos-chem-phys.net/4/2313/2004/.

Ramonet, M., Schmidt, M., Pépin, L., Kazan, V., Picard, D., Filippi, D., Jourd'heuil, L., Valant, C., Monvoisin, G., Sarda, R., and Ciais, P.: The French Trace Gas Monitoring Program RAMCES, in: Report of the Eleventh WMO/IAEA Meeting of Experts on Carbon Dioxide Concentration and Related Tracer Measurement Techniques, WMO/GAW Report 148, edited by: Sasaki Toru and Suda Kazuto, Tokyo, Japan, 136-148, 2003.

Rasch, P. J. and Kristjansson, J. E.: A comparison of the CCM3 model climate using diagnosed and predicted condensate parameterizations, J. Climate, 11, 1587-1614, 1998.

Rasch, P. J., Mahowald, N. M., and Eaton, B. E.: Representations of transport, convection and the hydrologic cycle in chemical transport models: Implications for the modeling of short-lived and soluble species, J. Geophys. Res., 102, 28 127-28 138, 1997.

Rasch, P. J., Feichter, J., and Law, K.: A comparison of scavenging and deposition processes in global models: results from the WCRP Cambridge Workshop of 1995, Tellus, 52B, 1025-1056, 2000.

Reithmeier, C. and Sausen, R.: ATTILA atmospheric tracer transport in a Lagrangian model, Tellus B, 54, 278-299, 2002.

Roeckner, E., Arpe, K., Bengtsson, L., Christoph, M., Claussen, M., Dümenil, L., Esch, M., Giorgetta, M., Schlese, U., and Schulzweida, U.: The atmospheric general circulation model ECHAM-4: Model description and simulation of present-day climate, MPI Technical Report 218, Max Planck Institute for Meteorology, Hamburg, Germany, 1996.
Roeckner, E., Bäuml, G., and Bonaventura, L.: The atmospheric general circulation model ECHAM 5. PART I: model description, MPI Technical Report 349, Max Planck Institute for Meteorology, Hamburg, Germany, 2003.

Roeckner, E., Brokopf, R., Esch, M., Giorgetta, M. A., Hagemann, S., Kornblueh, L., Manzini, E., Schlese, U., and Schulzweida, U.: Sensitivity of Simulated Climate to Horizontal and Vertical Resolution in the ECHAM5 Atmosphere Model, J. Climate, 19, 3771-3791, 2006.

Schery, S. D. and Wasiolek, M. A.: Modeling Radon Flux from the Earth's Surface, in: Radon and Thorn in the Human Environment, Proceedings of the 7th Tohwa University International Symposium, edited by: Katase, A. and Shimo, M., World Scientific Publishing Co. Pre. Ltd., Singapore, 73-78, 1998.

Shi, H.-B., Zhou, T.-J., Wan, H., Wang, B., and Yu, R.-C.: SMIP2 Experiment-based Analysis on the Simulation and Potential Predictability of Asian Summer Monsoon, Chinese J. Atmos. Sci., 32, 26-52, 2008.

Song, X.-L.: Evaluation of two mass-flux type cumulus parameterizations in climate simulations, $\mathrm{PhD}$ dissertation, Institute of Atmospheric Physics, Chinese Academy of Sciences, Beijing, China, p. 159, 2005.

Taylor, K. E.: Summarizing multiple aspects of model performance in a single diagram, J. Geophys. Res., 106, 7183-7192, 2001.

Tiedtke, M.: A comprehensive mass flux scheme for cumulus parameterization in large scale models, Mon. Weather. Rev., 117, 1779-1800, 1989.

Tost, H., Jöckel, P., and Lelieveld, J.: Influence of different convection parameterisations in a GCM, Atmos. Chem. Phys., 6, 54755493, 2006, http://www.atmos-chem-phys.net/6/5475/2006/.

Turekian, K. K., Nozaki, Y., and Benninger, L. K.: Geochemistry of atmospheric radon and radon products, Annu. Rev. Earth Pl. Sc., 5, 227-255, 1977.

van Ulden, A. P. and van Oldenborgh, G. J.: Large-scale atmospheric circulation biases and changes in global climate model simulations and their importance for climate change in Central Europe, Atmos. Chem. Phys., 6, 863-881, 2006, http://www.atmos-chem-phys.net/6/863/2006/.

Wan, H., Wang, B., Yu, R.-C., and Yu, Y.-Q.: Development and validation of the gridpoint atmospheric model of IAP LASG (GAMIL), Technical Report 16, LASG, Institute of Atmospheric Physics, Chinese Academy of Sciences, Beijing, P. R. China, p. 78, 2006

Wang, B. and Ji, Z.-Z.: New numerical methods in atmospheric sciences and their applications, Science Press, Beijing, P. R. China, p. 208, 2006 (in Chinese).

Wang, B., Wan, H., Ji, Z.-Z, Zhang, X., Yu, R.-C., Yu, Y.-Q., and Liu, H.-T. : Design of a new dynamical core for global atmospheric models based on some efficient numerical methods, Science in China, Series A, 47, 4-21, 2004.

Wilkening, M. H.: Daily and annual courses of natural atmospheric radioactivity, J. Geophys. Res., 64, 521-526, 1959.

Xie, P. and Arkin, P. A.: Global Precipitation: A 17-Year Monthly Analysis Based on Gauge Observations, Satellite Estimates, and Numerical Model Outputs, B. Amer. Meteorol. Soc., 78, 25392558, 1997.

Yang, J.-L., Wang, B., Guo, Y.-F., Wan, H., and Ji, Z.-Z.: Comparison Between GAMIL and CAM2 on Interannual Variability 
Simulation, Adv. Atmos. Sci., 24, 82-88, 2007.

Yu, R.: A Two-step shape-preserving advection scheme, Adv. Atmos. Sci., 11, 479-490, 1994.

Yu, Y.-Q., Zheng, W.-P., Wang, B., Wan, H., Liu, H.-L., Li, W., and Zhou, T.-J.: Coupled Model Simulations of Climate Changes in the 20th Century and Future, Adv. Atmos. Sci., accepted, 2008.

Zahorowski, W., Chambers, S., Wang, T., Kang, C.-H., Uno, I., Poon, S., Oh, S.-N., Werczynski, S., Kim, J., and HendersonSellers, A.: Radon-222 in boundary layer and free tropospheric continental outflow events at the three ACE-Asian sites, Tellus, 57B, 124-140, 2005.

Zahorowski, W. and Whittlestone, S.: Radon database 1987-1996: a review, in: Baseline Atmospheric Program (Australia) 1996, edited by: Gras, J. L., Derek, N., Tindale, N. W., and Dick, A. L., Bureau of Meteorology and CSIRO Atmospheric Research, Melbourne, 71-80, 1999.

Zaucker, F., Daum, P. H., Wetterauer, U., Berkowitz, C., Kromer, B., and Broecker, W. S.: Atmospheric ${ }^{222} \mathrm{Rn}$ measurements during the 1993 NARE Intensive, J. Geophys. Res., 101, 29149 $29164,1996$.
Zeng, Q., Yuan, C., Zhang, X., and Bao, N.: Tests of the finitedifference schemes of a general circulation model, Acta Meteorologica Sinica, 43, 441-449, 1985.

Zellweger, C., Klausen, J., and Buchmann, B.: System and Performance Audit of Surface Ozone and Carbon Monoxide at the Global GAW Station Hohenpeissenberg, Germany, WCC-Empa Report 06/3, WMO World Calibration Centre for Surface Ozone, Carbon Monoxide and Methane, Empa Dübendorf, Switzerland, p. 41, 2006.

Zhang, L. G., Guo, Q. J., and Iida, T.: Atmospheric radon levels in Beijing, China, Radiat. Prot. Dosim., 112, 449-453, 2004.

Zhang, G. J. and McFarlane, N. A.: Sensitivity of climate simulations to the parameterization of cumulus convection in the Canadian Climate Centre general circulation model, Atmos.-Ocean, 33, 407-446, 1995.

Zhang, K., Wan, H., Wang, B., and Zhang, M.-G.: Consistency problem with tracer advection in the atmospheric model GAMIL, Adv. Atmos. Sci., 25, 306-318, 2008. 